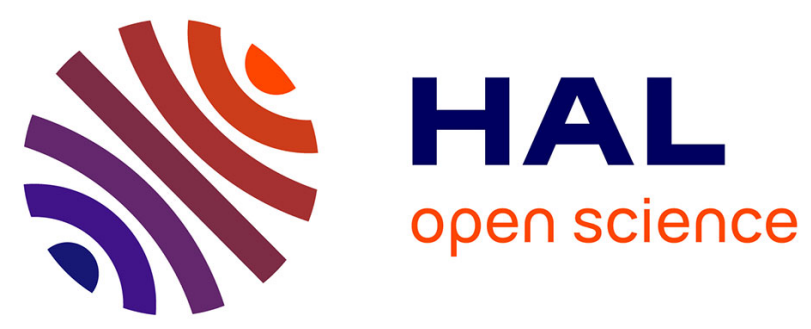

\title{
Resin-free three-layered Ti/PMMA/Ti sandwich materials: Adhesion and formability study
}

Melania Reggente, Mohamed Harhash, Sébastien Kriegel, Wenjia He, Patrick Masson, Jacques Faerber, Geneviève Pourroy, Heinz He, Adèle Carrado

\section{To cite this version:}

Melania Reggente, Mohamed Harhash, Sébastien Kriegel, Wenjia He, Patrick Masson, et al.. Resinfree three-layered Ti/PMMA/Ti sandwich materials: Adhesion and formability study. Composite Structures, 2019, 218, pp.107-119. 10.1016/j.compstruct.2019.03.039 . hal-02190404

\section{HAL Id: hal-02190404 \\ https://hal.science/hal-02190404}

Submitted on 22 Oct 2021

HAL is a multi-disciplinary open access archive for the deposit and dissemination of scientific research documents, whether they are published or not. The documents may come from teaching and research institutions in France or abroad, or from public or private research centers.
L'archive ouverte pluridisciplinaire HAL, est destinée au dépôt et à la diffusion de documents scientifiques de niveau recherche, publiés ou non, émanant des établissements d'enseignement et de recherche français ou étrangers, des laboratoires publics ou privés.

\section{(ㅇ)(1) $\$$}

Distributed under a Creative Commons Attribution - NonCommerciall 4.0 International 


\section{Resin-free three-layered Ti/PMMA/Ti sandwich}

\section{materials: adhesion and formability study}

Melania Reggente ${ }^{* a, b, 1}$, Mohamed Harhash $^{a, c}$, Sebastien Kriegel ${ }^{b}$, Patrick Masson $^{b}$ Jacques Faerber $^{b}$, Geneviève Pourroy ${ }^{b}$, Heinz Palkowski $^{* a}$ and Adele Carradò ${ }^{b}$

${ }^{a}$ Causthal University of Technology, Inst it ut e of Metallurgy (IMET), Robert-Koch-Strasse 42, 38678 Clausthal -Zell erfeld, Ger many.

${ }^{\text {b}}$ Univer sit é de Strasbourg, CNRS UMR 7504, Inst tut de Physique et Chimie des Mat ér iaux de Strasbourg (IPCMS), 23 rue du Loess BP 43, 67034 Strasbourg, France.

${ }^{c}$ Depart ment of Metallurgical and Mater ials Engineer ing, Faculty of Petroleumand Mining Engineer ing, Suez University, P.O. Box 43721, Suez, Egy pt.

${ }^{1}$ Pr esent Address: Inst itute of Chemical Sc iences and Engineer ing (ISIC), École Polyt echnique Féd éral e de Lausanne (EPFL), Stat ion 6, CH-1015 Lausanne, Swit zerland 


\section{Introduction}

Skull injuries caused by trauma and pathologies, such as tumor, infectious diseases or congenital defor mit ies, may r esult into ser ious funct ional, aest het ical and psychological sequels, requiring the reconstruction of complex craniofacial prostheses. In this field, the choice of suitable biomaterials is the ma in challenge. Currently, different classes of mono-materials, such as polymer s, cera mics and 1 ight metals are empl oyed to fabr icate skull and mandible prostheses ${ }^{1}$. In particular, poly(methyl methacrylate) (PMMA) $)^{2}$, polyether ether ketone (PEEK) ${ }^{3-4}$, hydroxya pat ite $(\mathrm{HA})^{5-7}$ and titanium $(\mathrm{Ti})^{4,6,8}$ are the most widely used materials in the cranioplasty reconstruct ion. Ti rema ins the most widely used metal in biomedical a ppl ications due to its biocompatibility ${ }^{9-11}$. In particular, Ti-based plates are generally used to built-up craniofacial prosthesis and replace the bone. As an example, light Ti skull and mandible prostheses are fabricated by using Sel ect ive Laser Melt ing or 3Dreconstruct ion techniques from medical images, which also reduces the possibility of errors during surgery ${ }^{12-15}$. Moreover, PMMA is al so ext ensively used in cranioplasty, due to it s biocompat ibil ity, strength, low cost and the possibility of preoperative use ${ }^{16-17}$. On the other hand, these materials are used as mater ials in food processing where biological a spects have to be taken int o account.

However, the mono-materials present many drawbacks, such as inappropriate mechanical properties or their high weight in the case of metals. For medical use, the discrepancy exist ing between the mechanical propert ies and the density of the implant and the bone to be replaced result $\mathrm{s}$ in stress shiel ding which represent s the most 1 imit ing fact or for a successful subst it ut $\mathrm{e}^{18,19}$. Since the mono-materials alone cannot solve this discrepancy in an optimal way, the development of hybrid structures - made of polymers and metal s exhibit ing new funct ional it ies can be a suitable approach in many fields of appl icat ion ${ }^{20}$. Indeed, they take the advantage of 
exploit ing both the low density and the light weight, specif ic of polymer ${ }^{21}$, and the high bending resistance and load ca pacity proper of the metal $\mathrm{s}^{20}$. Ther efore, by combining these two mater ials, structures possessing new properties, such as high-energy absor ption, high corrosion and mechanical resistance coupled with a lightweight, can be fabricated ${ }^{22}$. In particular, layered structures, such as sandwich mater ials, composed of two metall ic skin sheets and a polymer core can be an interest ing alternative to design innovative parts ${ }^{23}$. Such sandwich structures are used in the aircraft, automotive and naval industry because of their high acoust ic and damping capacity ${ }^{24-25}$, high stiffness and strength, good for mabil ity and 1 ightweight ${ }^{20,26-28}$. In these syst ems, an epoxy resin is commonly used as an adhesive agent to st ick the polymer core onto the metal skin sheets ensuring good bonding between the two components even under shear $\operatorname{load}^{23}$. The toxicity of this adhesive layer ${ }^{29}$ evidently prevents their a ppl icat ion in the biomedical field and food production. In our previous work ${ }^{23}$, it was shown that, following the rule of mixtures, the mechanical propert ies of the whole sandwich can be tail ored according to the skin and core thicknesses (or rather their volume fractions) achieving sandwich configurations with desir ed propert ies. In this way, structures with the necessary and designed st iffness and strength can be produced. Mor eover, their for mabil ty int o compl ex shapes - as r equir ed in the fabr icat ion of prostheses or special parts in industry - can be assured by select ing the proper sandwich components, adjust ing the skin/core thickness configurat ion and improving the metal/polymer bonding strength.

Although sandwich structures seem to be well adapt ed to the mechanical propert ies r equired in biomater ial s, the use of an epoxy resin is a ser ious drawback for in vivo a ppl icat ions and if being used in the food industry ${ }^{29}$. Thus, in order to extend their applications, the challenge is to establ ish a strong, biocompatible bonding between metal and polymer to include a polymer 
component between two metal sheets without using an epoxy resin able to attenuate stressshiel ding effects.

In general, the durability of a polymer-metal interface strongly depends on the adhesion strength between the two components. Since chemical bonds between metal and poly mer are not spontaneously establ ished, these layered hybrid polymer-metal mater ial s oft en exhibit undesired delamination phenomena due to a weak interfacial adhesion between metal and polymer resulting in the premature failure of the ent ire syst em ${ }^{30,31}$. Thus, recently grafted polymers (i.e. polymer chains with an extremity coval ently bound to a substrate) were proposed as adhesives to be inserted between a metal substrate and a polymer coating ${ }^{31-35}$. In particular, it has been shown that by exploit ing the miscibil ity bet ween the surface-confined polymer chains and those of a bulk ${ }^{36-40}$, melt ${ }^{33}$ or solut ion polymer ${ }^{35}$, the metal/poly mer adhesion strength is enhanced and their durabil ity improved ${ }^{31,33,35}$. Indeed, when two compatible polymers (i.e. polymer of the same nature) enter in int imate contact, a partial int er penetrat ion bet ween the cha ins of $t$ wo mat er ial $s$ is establ ished, according to the diffusion theory described by the reptation model ${ }^{39-41}$, and, as a result, entangl ements points are created ${ }^{37,38}$. The degree of inter penetration depends on three ma in factors: (i) the brushes surface density (i.e. the number of grafted chain per $\mathrm{nm}^{2}$ ); (ii) the brushes cha ins length; and (iii) the mol ecular weight distr ibut ion (MWD) ${ }^{37,38,42,43}$. Long cha ins in the low-density regime (al so called as mushroom regime) are requir ed to obtain a good penetration. Since in this regime the overlap between adjacent chains are avoided, they have enough free-volume to move, re-arrange and inter penetrate in the adher ing material ${ }^{37,38}$. It has also been demonstrated that higher chain lengths result in an improvement of the adhesiveness bet ween the polymer bulk and the brushes ${ }^{37}$. In particular, an increase of the tensil e strength of a junction formed by grafted PMMA chains interpenetrated in a melted PMMA matrix were 
reported when longer brushes chains were considered, due to a deeper penetrat ion of the PMMA brushes into the bulk PMMA ${ }^{33}$. Since, it has been demonstrated that brushes with a degree of polymer ization (i.e. the ratio between the molecular weight of the grafted chains and the mol ecular mass of the monomer) greater than or equal to 200 is necessary to establ ish physical entanglements with the adjacent polymer bulk $\mathrm{k}^{37}$, the opt imizat ion of coating methods enabl ing the product ion of fil ms with largethicknesses (few micrometres) are desired ${ }^{44}$.

In this context, the idea of this work was to employ surface-confined polymers to fabricate biocompat ible resin-free sandwich materials by sticking the polymer core on the metall ic skins previously coated with grafted polymer chains. As proof of concept for biomedical appl ications, Ti and PMMA were employed and Ti/PMMA/Ti sandwiches produced. Indeed, despite the significant discrepancy between the mechanical properties of Ti and those of the surrounding $\mathrm{t}$ issues, which often results in a stress shielding ${ }^{9,10}$. In order to reduce this tissue-implant mechanical impa ir ment, a technique to incor porate a polymer component to Ti implants was developed and sandwich materials, made of two Ti skins and a PMMA core, were produced using grafted polymer chains as an adhesive. Therefore, surface-confined PMMA chains replaced the epoxy resin layer and the adhesion between these tethered chains and those of an adher ing PMMA sheet (used as core mater ial) was establ ished by exploit ing their miscibility through the for mat ion of entangl ements. In particular, the PMMA cha ins were grown on alkal iactivated Ti surfaces ${ }^{45}$ through surface-init iated atom transfer radical polymer ization (SIATRP $^{46}$ using phosphonic acid derivatives as coup ing agents and malononitrile as polymer izat ion act ivator ${ }^{47,48}$. Being the establ ished graduate structure character ized by a high Ti/PMMA adhesion strength ${ }^{45}$, high thickness (i.e. long PMMA cha ins) ${ }^{45}$ and a porous structure (i.e. high free volume $)^{45,49}$ the possibility to use these PMMA-coated Ti surfaces for the 
product ion of sandwich is shown here. Indeed, Ti/PMMA/Ti sandwiches were obtained by hotpressing, exploit ing the inter penetrat ion bet ween the grafted PMMA chains and those of an adher ing PMMA foil used as core material ${ }^{31-37}$. Mor eover, the Ti/PMMA/Ti bonding strength, mechanical propert ies and for ming behaviour were evaluated perfor ming pull-off test $\mathrm{s}$, standard tensil e, bending, Er ichsen and deep-drawing test s,r espect ively.

\section{Experimental}

\subsection{Sample preparation}

PMMA foils ( $0.5 \mathrm{~mm}$ thick) containing $\mathrm{Ba} \mathrm{SO}_{4} \mathrm{f}$ illers and Grade 2 Ti sheet s of differ ent sizes (20 $\times 20 \times 0.4 \mathrm{~mm}^{3}, 20 \times 60 \times 0.4 \mathrm{~mm}^{3}, 20 \times 80 \times 0.4 \mathrm{~mm}^{3}, 20 \times 80 \times 0.2 \mathrm{~mm}^{3}, 25 \times 100 \times 0.4$ $\mathrm{mm}^{3}, 70 \times 70 \times 0.4 \mathrm{~mm}^{3}, 105 \times 148 \times 0.2 \mathrm{~mm}^{3}$ ) were used. These sizes were chosen with respect of the minimal sized requested by each mechanical test performed (e.g., pull-off, bending, drawing). Before operation, PMMA foil s were rinsed several times with ethanol and Ti sheets cleaned by ultrasonication in acetone, ethanol, and deionized water, 10 min each. The solvents were purchased from Carlo Er ba.

\subsection{Grafting of PMMA chains on Ti substrates}

PMMA chains were grafted onto Ti substrates using a three steps strategy previously devel oped ${ }^{45}$. With respect to this methodology, only the graft ing condit ions were opt imized by considerably reducing the treat ment time and the in it iat or concentration. Fir stly, Ti surfaces were activated by immersing the $\mathrm{Ti}$ sheets for $1 \mathrm{~h}$ in a $2 \mathrm{M}$ sodium hydroxide $(\mathrm{NaOH})$ concentrated aqueous solution heated up to $80^{\circ} \mathrm{C}^{45}$. Secondly, a synthesized bromoisobutyrate- 
undecyl-1-phosphonic acid $\left(\mathrm{C}_{15} \mathrm{H}_{30} \mathrm{O}_{5} \mathrm{PBr}\right)$ was immobil ized on the Ti surfaces using a "graft ing from" method performed in a $0.05 \mathrm{M}$ in it iat or concentrated aqueous solution at $100^{\circ} \mathrm{C}$ for $3 \mathrm{~h}$; Thirdly, a SI-ATRP was carried out to grow the PMMA chains according to a previously descr ibed procedure ${ }^{45}$. The init iat or-modif ied sa mpl es were suspended in a flask equipped with a magnet ic bar, which was then degassed three times (by alternating vacuum and argon) and finally filled with argon. Reagents were then added to the flask according to the following order and concentrat ions: [Cu(I)Br ]: $14 \mathrm{mM}$; [PMDETA]: $12 \mathrm{mM}$; [an isol e]: $4.1 \mathrm{M}$; [malononitril e]: $14 \mathrm{mM}$; [MMA]: 5.3 M. Wher eas, because of the r equir ed greater sol ut ion vol ume, A6-sized Ti sheets were treated using the following conditions: $\mathrm{Cu}(\mathrm{I}) \mathrm{Br}$ ]: $3 \mathrm{mM}$; [PMDETA]: $3 \mathrm{mM}$; [anisole]: $3.7 \mathrm{M}$; [malononitrie]: $3 \mathrm{mM}$; [MMA]: $5.3 \mathrm{M}$. At the end of the polymerization reaction, the samples (hereafter called PMMA-coated Ti) were cleaned for $10 \mathrm{~min}$ in an ultrasonic bath containing methanol to remove the untethered polymer as well as the residues of $\mathrm{Cu}(\mathrm{I}) \mathrm{Br}$ and PMDETA.

\subsection{Chemical characterization of the grafted PMMA layers}

Aft er each step of the PMMA-coated Ti synthesis procedure (na mely, the alkal i treat ment, the graft ing of the initiat or and the polymer ization) the chemical propert ies of samples' surfaces were investigated. In particular, attenuated total reflection Four ier transformed infrared spectroscopy (ATR-FTIR) analysis - performed with a PerkinEmer spectrometer with a

resolut ion of $4 \mathrm{~cm}^{-1}$ - was used to scan the surface-ex posed chemical groups, whereas, energy dispersive x ray spectroscopy (EDX) allowed individuat ing surfaces' elemental composition. This latter analysis was carried out using a Quantax EDX system embedded in a cross Beam ${ }^{\circledR}$ 
Workstation AURIGA-Zeiss 405 Microscope. The analysis of the Ti/PMMA/Ti sandwich fracture surfaces after pull -off test s were studied on a Zeiss GeminiSEM 500 SEM fitted with an EDX syst em from EDAX (Octane E ite SDD detect or + TEAM soft ware).

\subsection{Morphological characterization of the grafted PMMA layers}

Scanning electron microscopy (SEM) was employed to follow the evolution of the surface mor phology after each steps of the synthesis procedure and to invest igate the result ing PMMAcoated Ti cross-sect ion. In part icular, the mor phology after the al kal $i$ activat ion, the graft ing of the init iat or and the SI-ATRP react ion was imaged with a crossBea m® Workstat ion AURIGAZeiss 405 Microscope. Instead, the sa mple's cross-sect ion was firstly prepared using a ion beam cross-pol isher (Hitachi IM4000+). The samples were cut with a metallographical saw and an edge fromt he backside was pol ished with a $25^{\circ}$ bevel ( $\mathrm{SiC}$ P1000 pa per ) to reduce the thickness of Tito pol ish by the ion beam. The cross pol ishing was then perfor med from the back side (6 $\mathrm{keV}, \mathrm{Ar}$ ). By this way, the organic materiel was protected by the Ti it self and very few exposed tothe ion bea m. Then it s features studied using SEM analysis conduct ed on a Zeiss Gemini SEM 500 SEM.

\subsection{Ti/PMMA/Ti sandwich production}

Resin-free Ti/PMMA/Ti sandwiches of different sizes were produced by hot-pr essing. A PMMA foil $0.5 \mathrm{~mm}$ thick, used as core material, was inserted between two PMMA-coated Ti sheets. Since the manufactur ing process, regarding the bond ing propert ies bet ween metal and polymer, is independent from the thicknesses of the partners, and with the aim of firstly proving the 
feasibil ity of producing suitable resin-free sandwich materials, the combinat ions test ed were chosen depending on the mater ials available.

Alayup of the thr ee component s was then hot -pr essed together above the PMMA glass transit ion temperature and melt ing temperature $\left(111^{\circ} \mathrm{C}\right.$ and $160^{\circ} \mathrm{C}$, r es pect ively). Bonding was achieved by exploit ing the inter penetration of the grafted PMMA chains into the chains of the adhering PMMA foil, which led to the for mat ion of entanglement $s^{31,33}$.

The ma in parameters involved in the hot -pressing process are t ime, temperature and pressure. The opt imized combinations of these three parameters for the Ti/PMMA/Ti sandwiches product ion were assessed perfor ming a parametric study. For each parameter, three values were considered as follows: $\mathrm{T}=170,180$ and $200^{\circ} \mathrm{C}, \mathrm{t}=30,60$ and $90 \mathrm{~min}$ and $\mathrm{p}=0.1,0.2$ and 0.4 MPa. Thus, the maximum number of parameter combinat ions (i.e. possible ex per iments) was $3^{3}$, which wer er educed to an opt imized number of 19 ex per iment s, by using a design of ex per iments (DoE) tool, namely Minitab (Minitab Inc.). Successively, the best condit ions for the sandwich product ion were chosen as the ones guarantying the highest value of bonding strength, evaluated perfor ming pull -off test $\mathrm{s}$. The opt imu $\mathrm{m}$ was ident ified with $\mathrm{t}=90 \mathrm{~min}, \mathrm{~T}=180^{\circ} \mathrm{C}$ and $\mathrm{p}=0.2$ MPa, so, Ti/PMMA/Ti of different sizes were produced under these condition to perform mechanical and for ming tests.

\subsection{Investigation of the Ti/PMMA/Ti cross-section microstructure}

The microstructure of the Ti/PMMA/Ti cross-sect ions were analysed by Opt ical microscopy. The sa mpl es were prepared by cutt ing, with a shear cutting bank, a small piece $\left(20 \times 10 \mathrm{~mm}^{2}\right)$ of a Ti/PMMA/Ti sandwich from an A6-sized one. Then, the cross-sect ion of the samples was 
mounted using cold mount ing resin and successively prepared for the observation by wetgrinding using $\mathrm{SiC}$ papers and pol ishing it with synthet ic pol ishing fibre cloth with diamond paste (in a sequence of 6, 3 and finally $1 \mu \mathrm{m}$ ). Finally, the pol ished Ti/PMMA/Ti cross-sect ions were observed by opt ical microscopy (Ol ympus IX70 and Zeiss Ax io Imager).

\subsection{Evaluation of the Ti/PMMA/Ti sandwich adhesion: Pull-off tests}

The Ti/PMMA/Ti adhesion strength was evaluated perfor ming pull -off tests. For these tests, sandwiches made of two $(20 \times 20) \mathrm{mm}^{2}$ Ti skin sheet s and a PMMA core $0.5 \mathrm{~mm}$ thick were produced using the conditions 1 isted in Table 2, at least three samples each in most of the conditions. A two-components adhesive (3M scotch-weld DP 490 Structural adhesive epoxy) was used to st ick their external surfaces onto an $(20 \times 20 \times 100) \mathrm{mm}^{3}$ stainl ess steel bar. Before

test ing, the glue was cured by heating it at $60^{\circ} \mathrm{C}$ for $24 \mathrm{~h}$, and then it was kept at room temperature for $48 \mathrm{~h}$. The sampl es were then mounted on the univer sal test ing machine and the test s perfor med using a speed of $0.1 \mathrm{~mm} / \mathrm{min}$.

\subsection{Evaluation of the Ti/PMMA/Ti sandwich adhesion: Shear-tests}

The shear resistance of the Ti/PMMA/TI sandwiches was evaluated perfor ming single shear tests using a univer sal test ing machine with an appl ied speed of $1 \mathrm{~mm} / \mathrm{min}$. Sandwiches of two PMMA-coated Ti sheets $\left(25 \times 100 \times 0.4 \mathrm{~mm}^{3}\right)$ and a PMMA core foil, $0.5 \mathrm{~mm}$ thick, were produced according to the opt imum processing conditions. A defined overlapping area of about 
$275 \mathrm{~mm}^{2}\left(25 \times 11 \mathrm{~mm}^{2}\right)$ based on the thickness and the yield strength of the Ti sheet s was chosen following ASTM D3165.

\subsection{Tensile properties of the Ti/PMMA/Ti sandwiches}

The mechanical properties of the Ti sheets, PMMA foil s as well as the ones of Ti/PMMA/Ti sandwiches made of two PMMA-coated Ti sheet $0.2 \mathrm{~mm}$ thick and a PMMA core $0.5 \mathrm{~mm}$ thick (here after noted as 0.2/0.5/0.2 sandwiches) were determined by uniaxial tensile testing. According to ASTM E8, tensile samples of Ti and Ti/PMMA/Ti sandwich were prepared. In particular, Ti/PMMA/Ti sandwich samples were cut from an A6-sized sandwich previously produced using the parameter described in sect ion 2.4.1. Wher eas, PMMA foil s were prepared and test ed according to EN ISO 527-3-1B-50.

\subsection{Forming behaviour of Ti/PMMA/Ti sandwiches}

The for ming behaviour of Ti/PMMA/Ti sandwiches were analysed performing three-point bending as well as deep drawing and Er ichsen tests. These test s allow ident ify ing and correlat ing the possible failure modes ar ising from for ming such threetayered sandwich materials under different loading conditions. In principle, failure can be expected in the for m of: 1) cracking of the outer Ti skin sheet, which is more probable for thin ones; 2) cracking of the core layer, especially if the core has br ittle nature; or 3) int erla minar delaminat ion in case of weak skin/core adhesion character ist ics. To this pur pose, combinat ions of sandwiches with different Ti size (20 
$\times 60 \mathrm{~mm} 2$ and $20 \times 80 \mathrm{~mm} 2)$ and thicknesses $(0.2 \mathrm{~mm}, 0.4 \mathrm{~mm})$ were produced under the obtained optimum conditions. The following symmetric and asymmetric Ti/PMMA/Ti conf igurat ions were produced: (i) $0.2 / 0.5 / 0.2$; (ii) $0.2 / 0.5 / 0.4$; (iii) $0.4 / 0.5 / 0.4$.

\subsubsection{Three-point bending tests}

The bending propert ies of the Ti/PMMA/Ti sandwiches were invest igated perfor ming thr ee-point bending tests using punch sizes of $3 \mathrm{~mm}$ and $6 \mathrm{~mm}$ in dia meter. In part icular, the $3 \mathrm{~mm}$ punch was used to invest igate the propert ies of the 0.2/0.5/0.2 and 0.4/0.5/0.4 sandwiches, while the 6 $\mathrm{mm}$ punch wastaken for the a symmetr ic $0.2 / 0.5 / 0.4$ ones. The test speed was kept constant at 0.3 $\mathrm{mm} / \mathrm{s}$.

The performed test strategy was the following: Firstly, the maximum achievable bending angle, defined as the ones at which a visible fail ure of the systems (l ist ed above) occurred, was deter mined. Secondly, to follow the development of the bent sandwiches' strains as well as the degree of their spr ingback, st epwise t est s were perfor med using a $45^{\circ}$ st ep sequence. For this, the test was stopped at the specif ied angle under load, the strain distribut ion and the spr ingback were eval uated and documented, prior to carrying on the next step. It is not eworthy to ment ion that the bending angle was controlled by the previously deter mined bending displacement according to the controll ing equat ion of DIN EN ISO 7438-2005.

The strain field was determined using photogrammetry (GOM Argus) for the different successive steps. For this analysis and for a precise evaluation, fine dot pattern $(0.5 \mathrm{~mm}$ point diameter with $1 \mathrm{~mm}$ distance of the adjacent dot centres) was etched on the Ti sheet s by means of an electrolyt ic marking system (EU-Classic, Östl ing Marking Systems GmbH). Successively, 
a GOM Argus system was used to deter mine the strains. The results were obtained in ter ms of the distribution of the major strain in a section along the sample length; in addition, 3D phot ogra mmetr ic images show the crit ical regions of the shaped samples.

Wher eas, the spring-back rat ios (K) are det er mined based on the angle ratio bet ween the angle after unl oading $\left(\square_{2}\right)$ with respect of the one in theloading condit ion $\left(\square_{1}\right)$ :

$$
K=\frac{\alpha_{2}}{\alpha_{1}}
$$

A small spring-back is achieved if the K value is close to 1 .

The spring-back degree $(K)$ is correlated to elastic modulus in the plane strain condit ion (E') according to the geometrical and mechanical propert ies of the test ed sheet $\mathrm{s}^{50}$ :

$$
K=4\left(\frac{R_{i} \times Y S}{E^{\prime} \times t}\right)^{3}-3\left(\frac{R_{i} \times Y S}{E^{\prime} \times t}\right)+1
$$

where $R_{i}$ is the in it ial bend radius before spring-back, $t$ is the sheet thickness, YS is it $s$ ield strength.

In (2) $\mathrm{E}^{\prime}$ is expressed as a funct ion of the Poisson ration (?? $)^{51}$ :

$$
E^{\prime}=\frac{E}{1-v^{2}}
$$

According to (2), lower springback (i.e., better angle stabil ity) is expected with lower YS/E rat io as well as lower Rt rat io.

\subsubsection{Deep-drawing tests}

The possibil ity of shaping for ms that are more compl ex was invest igat ed by test ing the for ming propert ies of Ti/PMMA/Ti sandwiches with different thicknesses $(0.2 / 0.5 / 0.2,0.4 / 0.5 / 0.4$ and the asymmetr ic $0.2 / 0.5 / 0.4)$. 
Deep-drawing tests were perfor med at room temperature (RT) unt il fail ure or complete cup drawing using a drawing rat io $\beta_{0}=1.8$, i.e., the ratio bet ween the dia met er s of the blank $(60 \mathrm{~mm})$ and punch $(33 \mathrm{~mm})$. During the test s, the drawing speed was kept constant at $0.5 \mathrm{~mm} / \mathrm{s}$. As the bending tests, deep drawing tests were performed stepwise based on the failure limit of the drawn sandwich samples. At $6.8 \mathrm{~mm}$, no visual cracking of the Ti skin sheets occurred. In this regard, the deep drawing was carried out first unt il a displacement of $5 \mathrm{~mm}$, progressively

followed up to $10 \mathrm{~mm}$ displacement s. Finally, the complete drawing of the test samples was accompl ished. Moreover, for comparison, the drawing properties of Ti sheets of $0.2 \mathrm{~mm}$ thickness and those of the PMMA foil s with a thickness of $0.5 \mathrm{~mm}$ were invest igat ed perfor ming the test s according to the sa me procedure.

\subsubsection{Erichsen test}

Er ichsen test s - giving infor mat ion on the stretching behaviour of sheet material - were carried out on 0.2/0.5/0.2 Ti/PMMA/Ti sandwiches. A standard $25 \mathrm{~mm}$ dia meter semi-spher ical punch was used. During the test, the punch displacement rate was kept constant at $0.5 \mathrm{~mm} / \mathrm{s}$. The forming limits were determined in terms of the corresponding punch displacement when cracking occurs (na mely the Er ichsen Index (IE)) and for ming force could be deter mined.

\section{Results}

\subsection{Grafted PMMA layer bounded on Ti surfaces}

The cross-sect ion of PMMA chains grafted on a Ti substrate obtained following a three-step strat egy $^{45}$ is shown in Figure 1a. In the fir st step, a chemical act ivat ion of the Ti surfaces in a 
basic media was performed to increase the hydroxyl groups' content enabl ing the phosphonic acid to anchor. This treatment represents the key element of the procedure and led to the for mat ion of a nanostructured porous layer (see the bottomtop-view micrograph in Figure 1b) the interconnected porosity of which was used as scaffold to dr ive the following polymer izat ion and to create a further mechanical interlocking between the substrate and the growing PMMA layer. In the second step, the ATRP in it iat or (2-bromo-2-methyl-propionic acid 11-phosphonoundecyl ester, $\mathrm{C}_{7} \mathrm{H}_{14} \mathrm{O}_{5} \mathrm{PBr}$ ) was grafted on the alkal i-act ivated Ti surfaces (see Figure $\mathbf{1 b}$ in the middle); the anchor ing was established by creating covalent Ti-O-P bonds bet ween the surface hydroxyl groups and the phosphonic acid der ivat ive $e^{45,47,48}$. Compared to our previous work ${ }^{45}$, we could reduce the $t$ ime of the graft ing treat ment from $24 \mathrm{~h}$ to $3 \mathrm{~h}$. Indeed, by measur ing the $\mathrm{pH}$ during the reaction, a plateau was reached after $3 \mathrm{~h}$ and no more variations were detected. Moreover, the ATRP initiat or concentration was decreased to $0.05 \mathrm{M}$ without noticing significant difference in the resulting surfaces previously treated with a $\sim 0.8 \mathrm{M}$ initiator concentration (for a mor phological and chemical comparison between a $3 \mathrm{~h}$ and a $24 \mathrm{~h}$ $\mathrm{C}_{7} \mathrm{H}_{14} \mathrm{O}_{5} \mathrm{PBr}$-modified $\mathrm{Ti}$ surfaces see Figure $\mathrm{S1}$ in the supplementary infor mation (SI)). Finally, in the third step, the hybrid PMMA-coated Ti surfaces were obtained by growing the PMMA chains fromt he init iat or -modified Ti surfaces. As highl ight ed by the SEM micrograph in Figure 1b (top) the polymer izat ion r eact ion results in a rounded PMMAlayer cover ing the ent $\mathbf{r}$ e surface, character ized by an underneath porosity local ized at the Ti/PMMA interface (Figure 1a) ${ }^{45,49}$.

Add it ionally, the effect of using a shorter ATRP init iat or (i.e., a commercial bromoisobutyratepropyl-1-phosphonic acid, $\mathrm{C}_{7} \mathrm{H}_{14} \mathrm{O}_{5} \mathrm{PBr}$ ) on the pol ymer thickness and struct ure was invest igat ed. Wher eas, a comparison between the surface morphologies before and after the graft ing of the 
two (different in size) initiator molecules together with the corresponding EDX spectra, is pr esent ed in Figure 2. The SEM micrographs highl ight that the surface features change after the graft ing react ion. In particular, the surface, modified with the shorter init iator (Figure 2b), was characterized by the organic molecules bounded around the pillars left by alkal i-act ivated Ti surfaces. Thus, it led to a mor phology simil ar to that of the microporous layer (Figure 2a) but less branched. Instead, the grafting of the longer init iat or results in a more compact structure composed of shar per pillars (Figure 2c). Thus, as expected, the longer init iat or filled up better the por es left by the al kal itreat ment. This reorganizat ion of the surfaces was al so conf ir med by EDX analysis, the spectra of which were used to deter mine their el emental composit ion. After the grafting reaction, the absence of the peak pertained to the sodium, visible after the alkali treat ment (Figure 2d), suggest s that the graft ing react ion leads to a reorganizat ion of both the surface mor phology and composit ion. Mor eover, the or ganic content (carbon peak at $0.277 \mathrm{keV}$ ) increases and the signal s relat ed to the bromine $(\mathrm{Br})$, t ypical of the $\mathrm{D}$-bromo est er group, and that attribut ed to the phosphorous (P) of the phosphonat es a ppear (Figure 2d and Figure 2e).

Then, taking into account the difference in the number of mols produced by using shorter mol ecul es, the reagent s quant ity requir ed for the polymer izat ion was recalculated in funct ion of the in it iat or's number of mols and the ATRP consequently carr ied-out. As pr eviously underl ined, the graft ing reaction with the shorter init iat or leads to a more open surface structure, which results in the growth of less densely packed PMMA layers (Figure 3). Indeed, it a ppears highly por ous and composed of globules of or ganic materials preferent ially grown around the pillars of the microporous layer. Thus, for the pur pose of this work, in order to get longer grafted PMMA chains, - guarantying a better int er penetrat ion int o the ones of the adher ing PMMA foil, and thus 
a stronger bond ${ }^{28}$ - the long bromoisobutyrate-undecyl-1-phosphonic acid ATRP in it iator was empl oyed.

\subsection{Production of Ti/PMMA/Ti resin-free sandwiches}

Successively, a procedure to st ick a $0.5 \mathrm{~mm}$ thick PMMA foil between two synthesized PMMA-coated Ti sheets was developed by replacing the epoxy resin, usually empl oyed in the fabrication of sandwich materials, with the previously grown tethered polymer chains. Thus, resin-free Ti/PMMA/Ti sandwiches were produced by hot-pressing. The best possible ex per imental condit ions for the Ti/PMMA/Ti sandwiches product ion wer e a ssessed perfor ming a para metr ic st udy using a design of ex per iments (DoE) method, adopt ing Minitab Inc. as tool for the data analysis. In part icular, in or der to r educe the number of the ex per iment s to be perfor med, an opt imal factorial DoE plan was a ppl ied by hypothesizing that the simultaneous int eract ion of the three parameters involved in the production (i.e. temperature, time and pressure) is negl igible. In this way, 19 experimental combinations (l isted in Table 1) were sel ected and Ti/PMMA/Ti sandwiches wer e accordingly produced.

Then, the corresponding Ti/PMMA adhesion strength was evaluated perfor ming pull -off test s using $(20 \times 20) \mathrm{mm}^{2}$ sandwich samples. The opt imum condit ions for the sandwich product ion were chosen as the ones guarantying the highest value of the bonding strength according to the data reported in Table 1 and the graphical representation in Figure 4. This latter shows the correlat ion bet ween hot -pr essing time and temperature at a constant pressure of 0.1 MPa (Figure 4a), 0.2 MPa (Figure 4b) and 0.4 MPa (Figure 4c), r espect ively. In general, it can be stat ed that by increasing the hot -pr essing t ime and/or the temper at ure, the pull -off strength improves. When a pressure of 0.1 MPa is a ppl ied (see Figure 4a), the maximum possible pull -off strength can be 
reached only at higher temperatures $\left(200^{\circ} \mathrm{C}\right)$, which is not recommended to be used. Indeed, it should be consider ed that the processing temperature should not over step or even come close to the degradat ion temperature of the PMMA foil $\left(\sim 205^{\circ} \mathrm{C}\right.$ see Figure SI.2), es pecially in case of long hot -pressing times. On the other side, by increasing the pressure to $0.4 \mathrm{MPa}$, the time required to reach the maximum pull -off strength is reduced, however, the temperat ure should be st 11 above $195^{\circ} \mathrm{C}$ to del iver high strengths (see Figure 4c). Mor eover, the high pr essur el ed to a squeeze-out of the PMMA core and/or the possible onset of the PMMA degradation, which can lead to undesired thickness inhomogeneit ies. Whereas, by applying a pressure of $0.2 \mathrm{MPa}$, the maximum pull -off strength can be r eached at an average temperature of $180{ }^{\circ} \mathrm{C}$ and a t ime more than 80 min (see Figure 4b). In this work, we selected the following process conditions: temperature $\mathrm{T}=180{ }^{\circ} \mathrm{C}$, t ime $\mathrm{t}=90 \mathrm{~min}$ and pressure $\mathrm{p}=0.2 \mathrm{MPa}$, which ensure the highest possibl e pull -off strength (24 MPa) a voiding a squeezing-out and degradat ion of the polymer.

\subsection{Evaluation of the Ti/PMMA/Ti adhesion strength}

The pull-off test s performed (as sketched in Figure 5a) on three Ti/PMMA/Ti sandwiches produced using the opt imized condit ions led to ther esults shown in Figure 5b. In part icular, two sampl es $\left(\mathrm{Ti} / \mathrm{PMMA} / \mathrm{Ti}_{1}\right.$ and $\left.\mathrm{Ti} / \mathrm{PMMA} / \mathrm{Ti}_{3}\right)$ br oke within the glue used to mount the sample to the steel support (see Figure 5a) indicat ing that the Ti/PMMA adhesion strength is higher than that of the Ti/st eel glue. Wher eas, in the last sampl e (Ti/PMMA/Ti-2) fail ure occurred within the PMMA sheet (at $024 \mathrm{MPa}$ ).

Mor eover, the Ti/PMMA/Ti fail ure mechanism was ident ified by analysing the mor phology and the chemical composition of the sandwich fracture surfaces after the pull-off tests (a representat ive image of which is shown in Figure 5c), by using SEM-EDX mea surement s. The 
EDX el emental analysis and the SEM micrographs of the PMMA foil (Figure 5e) - used as core material - showed that it contains $\mathrm{Ba} \mathrm{SO}_{4}$ fillers (white spots in Figure 5e). Since traces of $\mathrm{Ba} \mathrm{SO}_{4}$ particles were found al so in the Ti/PMMA/Ti surface fracture (SF) (see Figure 5c and EDX spectra in Figure 5d), we concluded that the fracture occurred within the PMMA core and consequently the fail ure mechanism is of cohesive nature. Addit ionally, the shear resistances of the sandwiches were evaluated performing single shear tests on Ti/PMMA/Ti samples as schemat ized in Figure 6a. Two metal sheets (schemat ized in black in Figure 6a) were inserted bet ween the sa mple and the jaws of the tensile machine in order to ensuret he axial ity and avoid bending phenomena dur ing the test s.

The r esult s of thr ee r epresent at ive Ti/PMMA/Ti sandwiches are shown in Figure $6 \mathbf{b}$. It can be point ed out that fail ure occurred within the PMMA foil (see the surface fracture in Figure 6c) for ultimate shear strength of $(10 \pm 2) \mathrm{MPa}$. For comparison, the shear resistance of three sandwiches composed of two brushed Ti sheet skins (0.4 mm thick) and a PMMA foil with a thickness of $0.5 \mathrm{~mm}$ were al so invest igated. The average Ti surface roughness aft er the brushing treat ment was found equal to $(2.7 \pm 0.3) \mu \mathrm{m}$, al most five t imes higher than those of the untreated ones $(0.5 \pm 0.1) \mu \mathrm{m}$. The r esults allowed evaluat ing a Ti/PMMA bond ing strength of $(0.9 \pm 0.1)$ MPa, which is much lower than those obtained using the PMMA-coated Ti sampl es. The weak Ti/PMMA adhesion strength is totally due to (the only) mechanical int erlocking of the PMMA int o the irr egularit ies of the Ti surfaces since no chemical treat ment was perfor med on the metal sheets and also due to the inertness behaviour of the PMMA, which possesses a low adhesiveness nat ure.

\subsection{A6-sized Ti/PMMA/Ti sandwiches: scale-up of the fabrication process}


In order to investigate both the mechanical properties and the forming behaviour of Ti/PMMA/Ti sandwiches, A6-sized Ti sheets $(105 \times 148) \mathrm{mm}^{2} \times 0.2 \mathrm{~mm}$ thick, were coated with grafted PMMA chains by employing a larger volume of solut ion ( 1000 ml ) contained in a bigger reactor. Despite a thicker PMMA layer was obtained in the part of the Ti sheet closer to the magnetic stirrer (due to an unsteady mixing of the reagents), the ent ire surface was completely covered (see Figure $\mathbf{S 3}$ in SI). Then, A6-sized Ti/PMMA/Ti sandwiches were produced by hot -pressing (see Figure 7a), as pr eviously explained, using a $0.5 \mathrm{~mm}$ thick PMMA foil as core material. The resulting sandwich cross-section, obtained by cutting a A6-sized sandwich, was analysed by optical microscopy and the corresponding image is displayed in Figure $7 \mathbf{b}$.

\subsection{Mechanical properties of Ti/PMMA/Ti sandwiches}

In order to study the mechanical propert ies of this system as well as the ones of Ti sheets and PMMA foils mono-materials, minitensile samples of Ti and Ti/PMMA/Ti sandwiches were prepared, according to ASTM E8. PMMA sampl es were prepared and tested according to EN ISO 527-3-1B-50. The results of the tensile tests are given in Figure 8. As expected, the Ti sheet s (black curves) exhibit the highest strength values with a Young's modulus of 108 GPa and an ult imate tensil e strength (UTS) of $441 \mathrm{MPa}$ as well as a strain at fail ure of 27\% (see Table 2), whil e the PMMA foil shows a brittle behaviour (blue curves). St iffness and UTSs values of the sa mpl es arel isted in Table 2.

The brittleness of the PMMA is expect ed to influence the stress-strain behaviour of the ent ire sandwich sheets under tensil eloading as well as the for ming behaviour under bending and deepdrawing loading condit ions. In this regard, it was observed that the PMMA core cracks earl ier 
than the pure $\mathrm{Ti}$ skin sheets in the sandwich (in strain range between $22 \%$ and $28 \%$, red curves) with a strain difference of about $2 \%$ at the end of the tensil e test ing (see black arrows in Figure 8). Nevertheless, the total el ongation of the Ti/PMMA/Ti sandwiches failures comes close to that ones of the Ti sheets. It is noteworthy to ment ion that even if there was a sl ight strain difference between the Ti and PMMA inside the sandwich sheet, no delaminat ion fail ure could be stated.

Further more, using the Ro $\mathrm{M}^{23}$ (Eq. (1)) the Young's modulus of the sandwich $\left(\mathrm{E}_{\mathrm{SMs}}\right)$ can be predicted using the PMMA (EPMMA) and Ti sheets $\left(\mathrm{E}_{\mathrm{Ti}}\right)$ Young's modul i combined with their volume fract ion ( $\mathrm{f}_{\mathrm{PMMA}}$ and $\mathrm{f}_{\mathrm{Ti}}$, r espect ivel $\mathrm{y}$ ), a s follows:

$$
E_{S M S}=f_{P M M A} E_{P M M A}+f_{T i} E_{T i}
$$

As stated befor $\mathrm{e}^{23}$, depending on the thickness $\mathrm{rat}$ io of the mono-materials, it is possible to design the mechanical propert ies of the ent ire sandwich system, according to the RoM. Thus, as an exa mple, with a high rat io of polymer the yield and ult imate tensile stresses (YS and UTS) as well as the Young's modulus (E) can be reduced, in order to reach propert ies comparable to that of the cortical bone $e^{50,51}$. Indeed, considering that the chosen Ti sheet and PMMA foil have a Young's modulus equal to $(108 \pm 7) \mathrm{GPa}$ and $(2.0 \pm 0.1) \mathrm{GPa}$, two combinat ions of the Ti and PMMA thicknesses r equir ed to get a Ti/PMMA/Ti sandwich possessing a st iffness of about 32 GPa and an UTS of $162 \mathrm{MPa}$ were suggest ed. Firstly, a symmetr ic structure (Ti/PMMA/Ti ${ }^{* 1}$ in Table 2), composed of two Ti sheets $0.2 \mathrm{~mm}$ thick and a PMMA foil $1.0 \mathrm{~mm}$ thick (corresponding to a PMMA volume fract ion equal to 0.71). Secondly, by ma intaining the sa me PMMA volume fract ion, an asymmetr ic Ti/PMMA/Ti combinat ion could be obtained using two 
Ti sheet s 0.2 and 0.4 mm thick and a PMMA core of $1.5\left(\mathrm{Ti} / \mathrm{PMMA} / \mathrm{Ti}^{* 2}\right.$ in Table 2$)$. This may result in a decrease of the bio-mechanical impa ir ment ex ist ing bet ween the bone and the implant .

\subsection{Forming properties of Ti/PMMA/Ti sandwiches}

The capability of shaping Ti/PMMA/Ti sandwiches was invest igated performing bending, Erichsen and deep-drawing tests. For this purpose, both, symmetric and asymmetric Ti/PMMA/Ti structures were analysed.

\subsubsection{Three-point bending test}

The bending properties of the TI/PMMA/Ti sandwiches were invest igated perfor ming threepoint bending test s using punch sizes of $3 \mathrm{~mm}$ and $6 \mathrm{~mm}$ in dia met er. As reported in Figure 9a, with a $6 \mathrm{~mm}$ punch all the tested samples (dashed lines) exhibited neither cracking nor delamination or interlaminar shearing at the sample edges up to a bending angle of $180^{\circ}$. Besides, the observed Ti/PMMA good adhesion, the duct i ity of the PMMA core was enough to accompl ish cracking-free bending operation in all the sandwich structures (Figure 9b). The bending force-displacement curve for the asymmetric sandwich $(0.4 / 0.5 / 0.2$, black, dashed 1 ine in Figure 9a) is located bet ween the two symmetr ic ones, i.e. $0.4 / 0.5 / 0.4$ and $0.2 / 0.5 / 0.2$. The punch was set in contact with the thinner Ti sheet, so the thicker (outer)layer could withstand a higher bending load. As ex pected, the bending tests carried-out with the smaller punch (dia met er of $3 \mathrm{~mm}$ ) on the symmetric sandwich combinat ions (i.e. $0.2 / 0.5 / 0.2$ and $0.4 / 0.5 / 0.4)$ result in an increase of the bending forces for both combinations tested (1 ight blue and red sol id lines in Figure 9a, r espect ively).

Mor eover, the sandwich combinat ion built up using the thinner Ti sheet s (i.e. the 0.2/0.5/0.2 sandwich), bent with 3 the $3 \mathrm{~mm}$ punch showed a significant decrease of the for ming 1 imit (sol id 
red line in Figure 9a). As depicted in Figure 9a, cracking (highl ighted in Figure 9c) took place at a punch displacement of a pprox. $16 \mathrm{~mm}$, corresponding to a bending angle of a pprox. $80^{\circ}$.

The previous bending results can be further explained by analysing the strain field on the surface of the bent Ti sampl es. Figure 10 shows the average value of the maximum major strain deter mined fromt he middle part of the bent sa mples shown in Figure 11. As ex pected, with the smaller punch size ( $3 \mathrm{~mm}$, the sol id 1 ines $)$ higher strain values resulted leading to earl ier fail ure by cracking at about $80^{\circ}$ in case of the thinner Ti sheet $(0.2 \mathrm{~mm})$.

Addit ionally, the strain level s, using the $6 \mathrm{~mm}$ punch, are less, even at higher bending angles, because of the reduced load on the out side of the sheet. The springback ratios (K) of the Ti/PMMA/Ti sandwiches in correlat ion with the skin/cor ethickness and the bending angl es $\left(45^{\circ}\right.$, $90^{\circ}$ and $135^{\circ}$ ) using the $3 \mathrm{~mm}$ and $6 \mathrm{~mm}$ punch diameters are shown in Figure 12.

Due to the high elast ic /low plast ic strain fraction exist ing at this angle for the first bending step $\left(45^{\circ}\right)$ lower K-values - higher springback angles - for all the sandwich results were observed. For the sa me sandwich sheets with the larger bending punch diamet er, lower K-values resulted,too, which is in accordance with the fundamental s of springback propert ies (as shown in (1)) Further more, the asymmetric sandwich $\left(0.4 / 0.5 / 0.2^{*}\right)$ shows an intermediate K-value progress with the bending angle, locat ed bet ween thet wo symmetr ic ones, i.e.the $0.2 / 0.5 / 0.2$ and 0.4/0.5/0.4. It can be stated, that bending of the sandwich sheets is in good agreement to the guidel ines recommended for monol thic sheet metals, where the radius of the bending punch (r) is suggested to be $t$ wice the sheet thickness ( $t)$, i.e. $r \geq 2 t$. Safe bending process can be achieved with a ratio of the punch radius $\mathrm{R}$ to the materials thickness of $3(\mathrm{R} t>3)$. For high strength material $\mathrm{s}, \mathrm{R}>5 \mathrm{t}$ may be required ${ }^{51}$. 


\subsubsection{Deep drawing}

Moreover, for analysing the possibil it ies of shaping more complex components, deep drawing and Er ichsen t est s were perfor med. Due to the br ittle behaviour of the PMMA (see Figure 8), the pure PMMA foil failed earl ier at a punch displacement of only $\sim 6 \mathrm{~mm}$ (see viol et line in Figure 13a and Figure 13b).

Whereas, all the Ti/PMMA/Ti sandwich combinations (0.4/0.5/0.4 (black), 0.4/0.5/0.2 (red), 0.4/0.5/0.2 (gr een) in Figure 13a) wer e compl et ely drawn without visual cracking of the Ti sk in sheets (see Figure 13c and Figure 13d in the particular case of a 0.2/0.5/0.2 Ti/PMMA/Ti structure), due to the good for ming behaviour of the latter one (bluel ine in Figure 13a).

Neverthel ess, in correspondence of a $6 \mathrm{~mm}$ punch displacement, a small decay of the force was observed, possibly indicat ing cracking of the polymer core. As no delamination occurred, the cracking of the polymer core was ignored with respect to the overall drawing behaviour of the whole sandwich. The drawing properties of the invest igated sandwich combination are summar ized in Table 3.

\subsubsection{Erichsen tests}

The cracking 1 imit of the sandwich sheet $(0.2 / 0.5 / 0.2,1$ ight bl ue curves in Figure 14a) is the same as for the Ti sheet (red curves in Figure 14a); however - as ex pected -the force of the sandwich is twice that of the pure Ti sheet. Although the PMMA foils (black curves) show a higher Er ichsen index IE of $10 \mathrm{~mm}$ compared to the sandwich sheet and the Ti one, the fail ure mechanism is totally different exhibit ing clearly a br ittle cracking mechanism (Figure 14b-d). Thus, we can state that the defor mation behaviour of the invest igated sandwiches is good and 
sufficient for a complex shaping. The fail ure of the PMMA foil is delayed by the supporting effect of the Ti sheets. Moreover, the cracking of the polymer can be avoided or delayed by processing under el evated temperatures or using a more duct il e PMMA derivate.

\section{Conclusions}

Surface-confined PMMA cha ins were successfully grown on large Ti substrates (upto DIN A6 size) through SI-ATRP coupled with a "grafting from" method using phosphonic acids as coupl ing agents to ensure the metal-polymer covalent bonding. They were used as adhesive layers for the fabrication of biocompatible resinfree sandwich materials produced by hotpressing. In part icular, tethered PMMA chains were used to replace the epoxy resin - usually empl oyed in sandwich material sto st ick the polymer core ont othe metal skin sheets - and ensure the bonding through the for mation of entanglements caused by the inter penetration of the tether ed PMMA chains into those of the PMMA core. Ti/PMMA/Ti sandwiches were processed demonstrating that, for the sandwich product ion, tethered polymer chains can replace epoxyresin. In this way, the opt imum Ti/PMMA/Ti sandwiches hot-pressing paramet ers (temperature, t ime and pressure), del iver ing the highest Ti/PMMA adhesion, were developed using an opt imal fact or ial exper imental plan defined by the design of experiments method. With the opt imum condit ions $\left(180^{\circ}, 90 \mathrm{~min}\right.$ and $0.2 \mathrm{MPa}$ ), a high bonding strength (pull -off strength higher than 20 $\mathrm{MPa}$ and a shear resistance of $10 \mathrm{MPa}$ ) and good for ming propert ies could be achieved. The mechanical propert ies deter mined by tensile testing showed that the failure of the sandwiches ma inl y depends on the fail ure strain of the Ti sk in sheet s; wher eas, the br ittle fail ure nat ure of the PMMA did not remarkably influence the fail ure strain of the sandwich. Addit ionally, the rule of mixt ure was ver if ied with the obtained st iffness- and strength r elated propert ies (E, YS, UTS and 
ER10). Apply ing this rule, two sandwich combinat ions (symmetr ic and asymmetric) possessing mechanical properties - especially Young's modulus - close to that of the cortical bone were proposed. Three-point bending and deep-drawing tests were perfor med to analyse the for ming behaviour. In particular, despite the low duct il ity of the PMMA core, delaminat ion-free bending operat ion up to $180^{\circ}$ were achieved without cracking of the Ti/PMMA/Ti sandwiches made of thicker Ti skin sheets $(0.4 \mathrm{~mm})$ for both bending punches $(3 \mathrm{~mm}$ and $6 \mathrm{~mm}$ in diameter). However, for the smaller bending punch the bending angle was 1 imited to $80^{\circ}$ if thinner Ti skin sheet s $(0.2 \mathrm{~mm})$ wer e used. Further more, Ti/PMMA/Ti could be compl etely deep-drawn without visual cracking of the Ti skin sheets, thanks to the good for ming behaviour of the metal. The same behaviour could be stated for the Er ichsen test, where the britte nature of PMMA has no negat ive influence on the for ming 1 imits or even on the Ti/PMMA interface qual ty, indeed no dela minat ion took place.

\section{Supplementary Information}

The following addit ional analyses are included: $(i)$ character izat ion of the grafted-Ti surfaces after 3h and 24h; (ii) Character izat ion of the PMMA melt ing and glass transit ion temperatures;

(iii) Mor phol ogical character izat ion of A6-sized PMMA-coat ed Ti sa mpl es.

\section{AUTHOR INFORMATION}

\section{Corresponding Author}

*melania reggente@epfl.ch

* heinz.palkowski@tu-clausthal.de 


\section{Acknowledgements}

We gratefully acknowl edge the financial support provided by the Ger man Research Foundat ion: DFG, grant no. PA 837/44-1, by IDEX Universit é of Strasbourg as well as Fr iedrich Gustav Theis Kaltwalzwerke GmbH for supplying us with the Ti sheet s.

\section{REFERENCES}

[1] S. Aydin, B. Kucukyuruk, B. s, S. Aydin, and G. Z. Sanus, "Cranioplasty: review of material s and techniques," Journal of Neurosciences in Rural Pract ice, vol .2, no. 2, p. 162, 2011.

[2] T. Or ig itano, R. Izquierdo, and L. B. Scannicchio, "Reconstruct ing compl ex cranial defect s with a pr efor med cranial prosthesis," Skull Base Surgery, vol . 5, no. 02, pp. 109-116, 1995.

[3] B. Lethaus, Y. Safi, M.ter Laak-Poort, A. Kl oss-Brandstäter, F. Banki, C. Robbenmenke, U. St einseifer, and P. Kessl er, "Cranioplasty with cust omized titanium and PEEK implant s in a mechanical stress model," Journal of Neurotrauma,vol .29, no. 6, pp. 1077-1083, 2012.

[4] A. Thien, N. K. King, B. T. Ang, E. Wang, and I. Ng, "Compar ison of polyetheretherketone and titanium cranioplasty after decompressive craniectomy," World neurosurgery, vol .83, no. 2, pp. 176-180, 2015.

[5] B. L. Eppl ey, L. Holl ier, and S. Stal, "Hydroxya pat ite cranioplasty: 2. cl inical ex per ience with a new quick-sett ing mater ial," Journal of Craniofacial Surgery, vol . 14, no. 2, pp. 209-214, 2003.

[6] Y. Ducic, "Tit anium mesh and hydroxya pat te cement cranioplasty: a report of 20 cases," Journal of Oral and Maxill ofacial Surgery, vol .60, no. 3, pp. 272-276, 2002. 
[7] P. D. Costant ino, C. D. Fr iedman, K. Jones, L. C. Chow, and G. A. Sisson, "Ex per imental hydroxya pat ite cement cranioplasty.," Plast ic and Reconstruct ive Surgery, vol. 90, no. 2, pp. 174-851992.

[8] M. Cabraja, M. Klein, and T.-N. Lehmann, "Long term results following titanium cranio plasty of large skull defects,” Neurosurgical Focus, vol . 26, no. 6, p. E10, 2009.

[9] T.P. Queiroz, R.S., de Molon, F.Á. Souza, R. Margonar, A.H.A. Thomazini, A.C. Guastaldi, E. Hochul i-Vieira, "In vivo evaluation of cp Ti implants with modified surfaces by laser beam with and without hydroxya pat ite chemical deposit ion and without and with ther mal treat ment : topogra phic character izat ion and hist omor phometr ic analysis in rabbit s", C inical oral invest igat ions, vol. 21, no. 2, pp. 685-699, 2017.

[10] C. Debry, N.E. Vrana, A. Dupret-Bor ies, Implantation of an Art ificial Larynx after Total Laryngect omy. N. Engl . J. Med. 2017, 376, 97-98.

[11] A. Carradò, F. Perr in-Schmitt, Q.V. Le, M. Giraudel, C. Fischer, G. Koenig, G. Koenig, L. Jacomine, L. Behr, A. Chalom, L. Fiette, A. Morlet, G. Pourroy, "Nanoporous hydroxya pat te/sodium titanate bilayer on titanium implants for improved osteoint egrat ion", Dental Materials, vol.33, no. 3, pp. 321-332, 2017.

[12] L.A. Dobr za [ski, A.D. Dobr za [ska-Danikiewicz, A. Acht el ik-Franczak, L.B. Dobr za [ski, M. Szindl er, T.G. Gaweł, "Por ous sel ect ive laser melted $\mathrm{Ti}$ and $\mathrm{Ti}_{6} \mathrm{Al}_{4} \mathrm{~V}$ mater ial s for medical appl icat ions. In Powder Metallurgy-Fundamentals and Case Studies. In Tech, 2017.

[13] S. Mueller, B. Hohlweg-Majert, R. Buergers, T. Steiner, T.E. Reichert, K.D. Wolff, M. Gosau, "The functional and aesthetic reconstruction of midfacial and orbital defects by 
combining free flaptransfer and craniofacial prosthesis", $\mathrm{C}$ inical oral invest igat ions, vol . 19, no. 2, pp. 413-419, 2015.

[14] A.L. Jardini, M.A. Larosa, R. Maciel Fil ho, C.A. de Carvalho Zavagl ia, L.F. Bernardes, C.S. La mbert, D.R. Calderoni, P. Khar mandayan, "Cranial reconstruct ion: 3D biomodel and custom-built implant created using addit ive manufacturing", Journal of Cranio-Maxillo-Facial Surgery, vol .42, no. 8, pp. 1877-1884, 2014.

[15] H. Rotaru, R. Schumacher, S.G. Kim, C. Dinu, "Sel ect ive laser melted t itanium implants: a new technique for the reconstruct ion of ext ensive zygomat ic compl ex defects", Maxillofacial pl ast ic and reconstruct ive sur gery, vol . 37, no. 1, pp. 1, 2015.

[16] G.J. Huang, S. Zhong, S.M. Susarla, E.W. Swanson, J. Huang, C.R. Gordon, "Craniofacial reconstruction with poly (methyl methacrylate) customized cranial implants" Journal of Craniofacial Surgery, vol. 26, no. 1, pp. 64-70, 2015.

[17] A. Ridwan-Pramana, P. Marcián, L. Borák, N. Narra, T. Forouzanfar, J. Wolff, "Structural and mechanical impl ications of PMMA implant shape and interface geometry in cranioplasty-A fin ite el ement study", Journal of Cranio-Maxillo-Facial Surgery, vol. 44, no. 1, pp. 34-44, 2016.

[18] M. Ridzwan, S. Shuib, A. Hassan, A. Shokri, and M. M. Ibrahim, "Problem of stress shiel ding and improvement to the hip implant designs: a review," Journal of Medical Science, vol. 7, no. 3, pp. 460-467, 2007.

[19] A. J. Ruys, Biomimet ic biomater ial s: struct ure and a ppl icat ions. El sevier, 2013. 
[20] B. Harr is, "A per spect ive view of composite mat er ial s development," Mater ial s \& Design, vol. 12, no. 5, pp. 259-272, 1991.

[21] R. F. Landel and L. E. Niel sen, Mechanical propert ies of polymers and composites. CRC Press, 1993.

[22] O. T. Thomsen, E. Bozhevolnaya, and A. Lyckegaard, Sandwich Structures 7: Advancing with Sandwich Structures and Materials: Proceedings of the 7th International Conference on Sandwich Structures, Aalborg University, Aalborg, Denmark, 29-31 August 2005. Springer Science \& Business Media, 2006.

[23] M. Harhash, A. Carradò, and H. Palkowski, "Lightweight t tianium/polymer $t$ itanium sandwich sheet for technical and biomedical application," Materialwissenschaft und Werkstofftechnik, vol. 45, no. 12, pp. 1084-1091, 2014.

[24] Y. S. Chen, T. J. Hsu, S. I. Chen, "Vibrat ion da mping character ist ics of la minated steel sheet”, Metallurgical transact ions A, vol.22, no. 3, pp. 653-656, 1991.

[25] E. Bernd, J. Buhl, "Metal Forming of Vibration-Damping Composite Sheets", Steel Research Int ernat ional, vol . 82, no. 6, pp. 626-631, 2011.

[26] G. D. Parf ttt, Adsorpt ion from sol ut ion at the sol id $\Lambda$ iquid int erface. Academic Pr, 1983.

[27] L. Librescu and T. Hause, "Recent developments in the model ing and behavior of advanced sandwich constructions: a survey," Composite structures, vol. 48, no. 1, pp. 1-17, 2000. 
[28] O. A. Sokolova, A. Carradò, and H. Palkowski, "Metal-polymer-metal sandwiches with local metal reinforcements: A study on for mabil ity by deep drawing and bending," Composite Struct ures, vol . 94, no. 1, pp. 1-7, 2011.

[29] E. L. Kost oryz, P. Y. Tong, C. C. Chappelow, J. D. Eick, A. G. Glaros, D. M. Yourtee, "In vitro cytotoxicity of sol id epoxy-based dental resins and their components" Dental Materials, vol. 15, no. 5, pp. 363-373, 1999.

[30] Y. Fujimoto, Y. Kobayashi, M. Yamaguchi, "Delamination of abluminal polymer of biol imus-el ut ing st ent .JACC: Cardiovascular Inter vent ions",vol . 5, no. 3, pp. e5-e6, 2012.

[31] C. Sun, F. Zhou, L. Shi, B. Yu, P. Gao, J. Zhang, and W. Liu, "Tr ibological propert ies of chemically bonded polyimide fil ms on sil icon with polyglycidyl methacrylate brush as adhesive layer,” Appl ied Surface Science, vol .253, no. 4, pp. 1729-1735, 2006.

[32] Y. Shaulov, R. Okner, Y. Levi, N. Tal, V. Gutkin, D. Mandler, A. J. Do mb, "Poly (methyl methacrylate) grafting onto stainl ess steel surfaces: a ppl icat ion to drug-el ut ing stents". ACS appl ied material s \& interfaces, vol . 1, no. 11, pp. 2519-2528, 2009.

[33] K. Shimizu, K. Mal mos, A. H. Hol m, S. U. Pedersen, K. Daasbjerg, and M. Hinge, "Improved adhesion between PMMA and stainless st eel modified with PMMA brushes," ACS Appl ied Mater ials \& Interfaces, vol .6, no. 23, pp. 21308-21315, 2014.

[34] K. Shimizu, K. Malmos, S. A. Spiegel hauer, J. Hinke, A. H. Hol m, S. U. Peder sen, K. Daasbjerg, and M. Hinge, "Durability of peek adhesive to stainless steel modified with aryldiazonium salts," Internat ional Journal of Adhesion and Adhesives, vol .51, pp. 1-12, 2014. 
[35] O. Alageel, M.-N. Abdallah, Z. Y. Luo, J. Del-Rio-Highsmith, M. Cerrut i, and F. Ta mimi, "Bonding metals to poly (methyl methacrylate) using aryldiazonium salts," Dental Materials, vol. 31 , no. 2, pp. 105-

114, 2015.

[36] M. Aubouy, G. Fredrickson, P. Pincus, and E. Raphaeel, "Endtethered chains in pol ymer ic matr ixes," Macromolecules, vol .28, no. 8, pp. 2979- 2981, 1995.

[37] W. S. Gutowski, S. Li, C. Fil ippou, P. Hoobin, and S. Pet inakis, "Int erface/ int er phase engineer ing of polymer s for adhesion enhancement : Part ii. theor et ical and technological aspects of surface-engineered inter phaseinterface systems for adhesion enhancement," The Journal of Adhesion, vol. 79, no. 5, pp. 483-519, 2003.

[38] S. W. Sides, G. S. Grest, M. J. Stevens, and S. J. Pl impton, "Effect of end tethered pol ymers on surface adhesion of glassy polymers," Journal of Pol ymer Science Part B: Polymer Physics, vol.42, no. 2, pp. 199-208, 2004.

[39] E. Raphael and P. De Gennes, "Rubber rubber adhesion with connect or mol ecules," The Journal of Physical Chemistry, vol.96, no. 10, pp. 4002-4007, 1992.

[40] K. Kunz and M. Stamm, "In it ial stages of interdiffusion of PMMA across an interface," Macromolecules, vol. 29, no. 7, pp. 2548-2554, 1996.

[41] R. Schnell, M. Stamm, and C. Greton, "Direct correlat ion between interfacial width and adhesion in glassy polymers," Macromol ecul es, vol. 31, no. 7, pp. 2284-2292, 1998

[42] C. Gay, "Wetting of a polymer brush by a chemically identical polymer melt," Macromolecules, vol. 30, no. 19, pp. 5939-5943, 1997. 
[43] C. F. Laub and J. T. Kober stein, "Effect of brush polydisper sity on the int er pha se bet ween end-grafted brushes and polymer ic matrixes," Macromol ecul es, vol . 27, no. 18, pp. 5016-5023, 1994.

[44] J. E. Fr iis, K. Br øns, Z. Sal mi, K. Shimizu, G. Subbiahdoss, A. H. Holm, O. Santos, S. U. Pedersen, R. L. Meyer, K. Daasbjerg, et al ., "Hydrophil ic polymer brush layers on stainl ess st eel using mult ilayered ATRP in it iat or layer," ACS Appl ied Materials \& Interfaces, vol . 8, no. 44, pp. 30616-30627, 2016.

[45]M. Reggente, P. Masson, C. Doll inger, H. Palkowski, S. Zafeiratos, L. Jacomine, D. Passeri, M. Rossi, N.E. Vrana, G. Pourroy, A. Carradò, "A novel alkal i-act ivat ion of titanium substrates to grow thick and covalently bound PMMA layers" ACS appl ied materials \& int erfaces, vol . 10, pp. 5967-5977, 2018.

[46] J. S. Wang, K. Matyjaszewski, “Controlled/“'iving”radical polymer izat ion. At omtransfer radical polymerization in the presence of transition-metal complexes", Journal of the Amer ican Chemical Society,

vol. 117, no. 20, pp. 5614-5615, 1995.

[47] G. Guerrero, P.H. Mutin, A. Vioux, "Anchoring of Phosphonate and Phosphinate Coupl ing Molecul es on Titania Particles" Chemistry of Materials, vol . 13, pp. 4367-4373, 2001.

[48] V. Vergnat, G. Pourroy, P. Masson, P., "Enhancement of styrene conversion in organic/inorganic hybrid materials by using malononitrile in controlled radical polymer izat ion", Pol ymer Int ernat ional, vol .62, no. 6, pp. 878-883, 2013. 
[49] M. Reggente, M. Natal i, D. Passeri, M. Lucci, I. Davol i, G. Pourroy, G., P. Masson, H. Palkowski, U. Hangen, A.Carradò, M. Rossi "Mult iscale mechanical character izat ion of hybr id Ti/PMMA layered materials" Colloids and Surfaces A: Physicochemical and Engineering As pect s, vol .532, pp. 244-251, 2017.

[50] Tekiner Z, “An ex per imental study on the examinat ion of springback of sheet metals with several thicknesses and propert ies in bending dies," Journal of Mat er ial s Processing Technology, vol. 145, no. 1, pp. 109-117, 2004.

[51] Marciniak Z, Duncan JL, Hu SJ, "Mechanics of sheet metal for ming," 2nd ed. Oxford, Bost on: Butterworth-Heinemann, 2002.

[52] J.Y. Rho, R. B. Ashman, and C. H. Turner, "Young's modulus of trabecular and cort ical bone material : ultrasonic and microtensil e measurements," Journal of Biomechanics, vol . 26, no. 2, pp. 111-119, 1993.

[53] P.K. Zysset, X. E. Guo, C. E. Hoffler, K. E. Moore, and S. A. Goldstein, "Ela st ic modulus and hardness of cort ical and trabecular bone lamellae measured by nanoindent at ion in the human femur," Journal of Biomechanics, vol .32, no. 10, pp. 1005-1012, 199. 


\section{Figures}

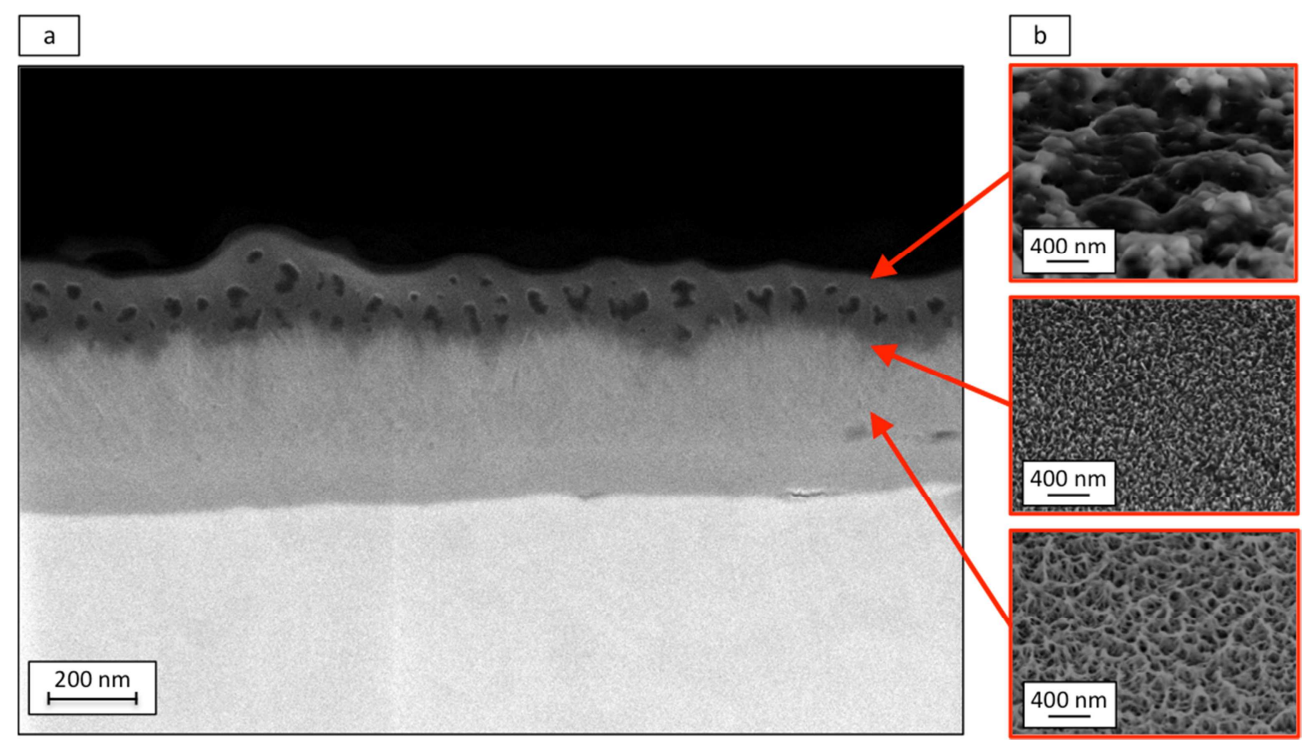

Figure 1: a) SEM image of a PMMA-coated Ticross-section, (b) the porous st ruct ure, typical for the alkali-activated $\mathrm{Ti}$ (bottom); the more compact $\mathrm{C}_{7} \mathrm{H}_{14} \mathrm{O}_{5} \mathrm{PBr}$ modified surface (middle); the st ructure of the grown PMMA layer (top). 

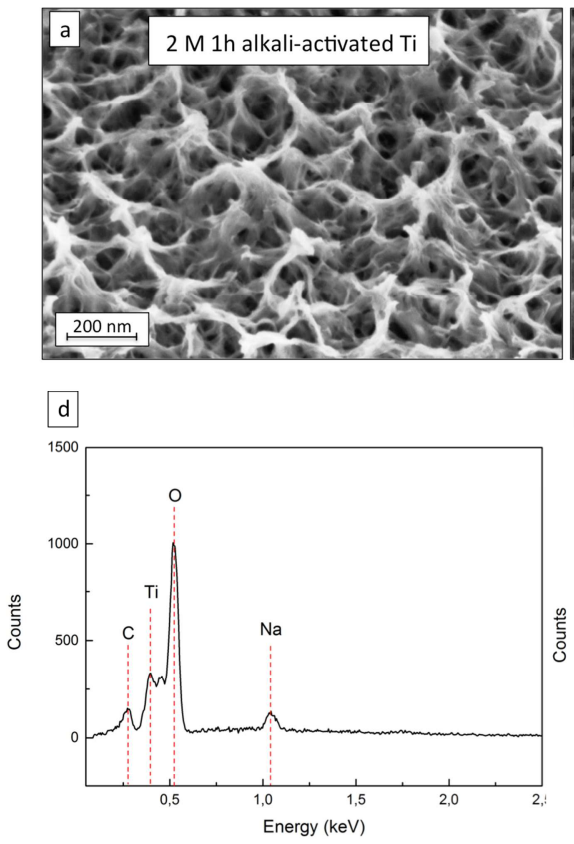

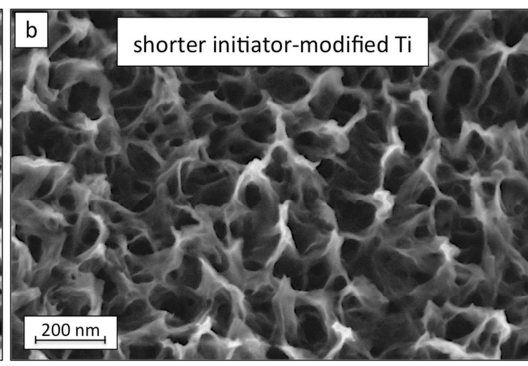

e

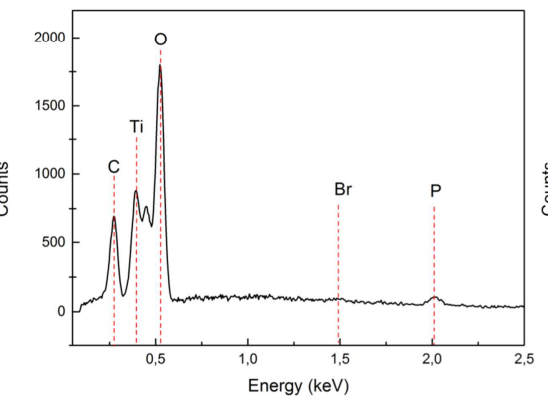

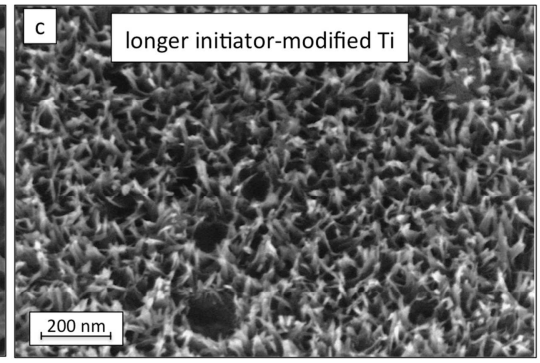

$f$

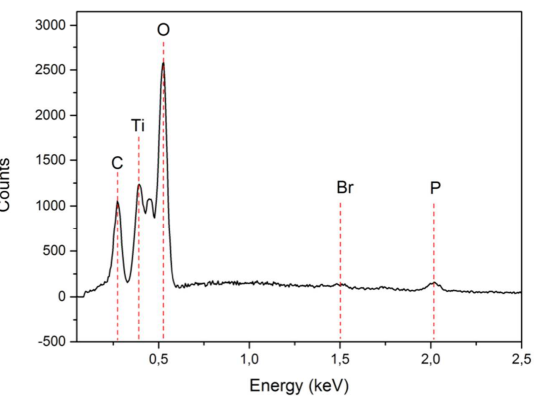

Figure 2: $\mathrm{SEM}$ micrograph of a : a ) al kal i-act ivat ed sur face; b) $\mathrm{C}_{7} \mathrm{H}_{14} \mathrm{O}_{5} \mathrm{PBr}$ in it iat or modif ied surface and c) $\mathrm{C}_{15} \mathrm{H}_{30} \mathrm{O}_{5} \mathrm{PBr}$ in it iat or modified surface. EDX spectra of: d) al kal i-activated surface; e) $\mathrm{C}_{7} \mathrm{H}_{14} \mathrm{O}_{5} \mathrm{PBr}$ initiat or modified surface and f) $\mathrm{C}_{15} \mathrm{H}_{30} \mathrm{O}_{5} \mathrm{PBr}$ in it iator modified surface.

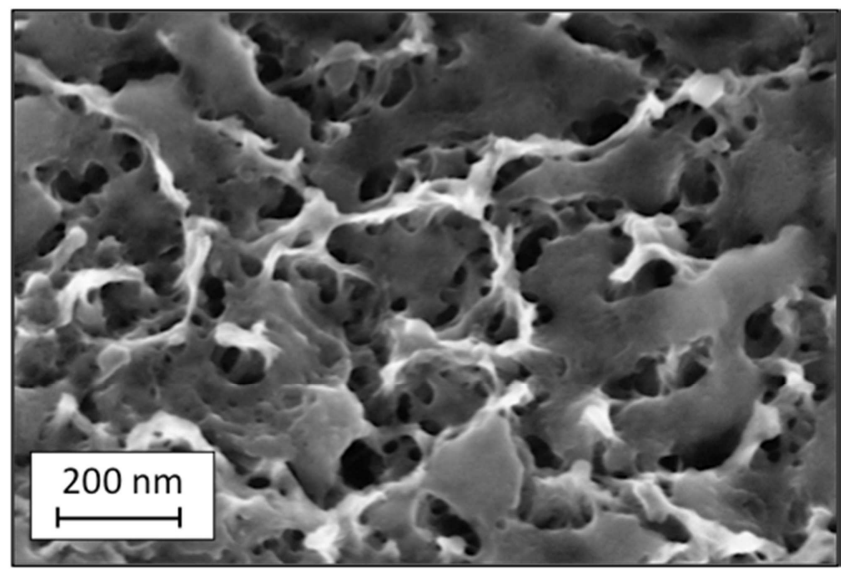

Figure 3: SEM micrograph of the PMMA layer grown starting from a short-initiator $\left(\mathrm{C}_{7} \mathrm{H}_{14} \mathrm{O}_{5} \mathrm{PBr}\right)$ modified Ti sur face. 

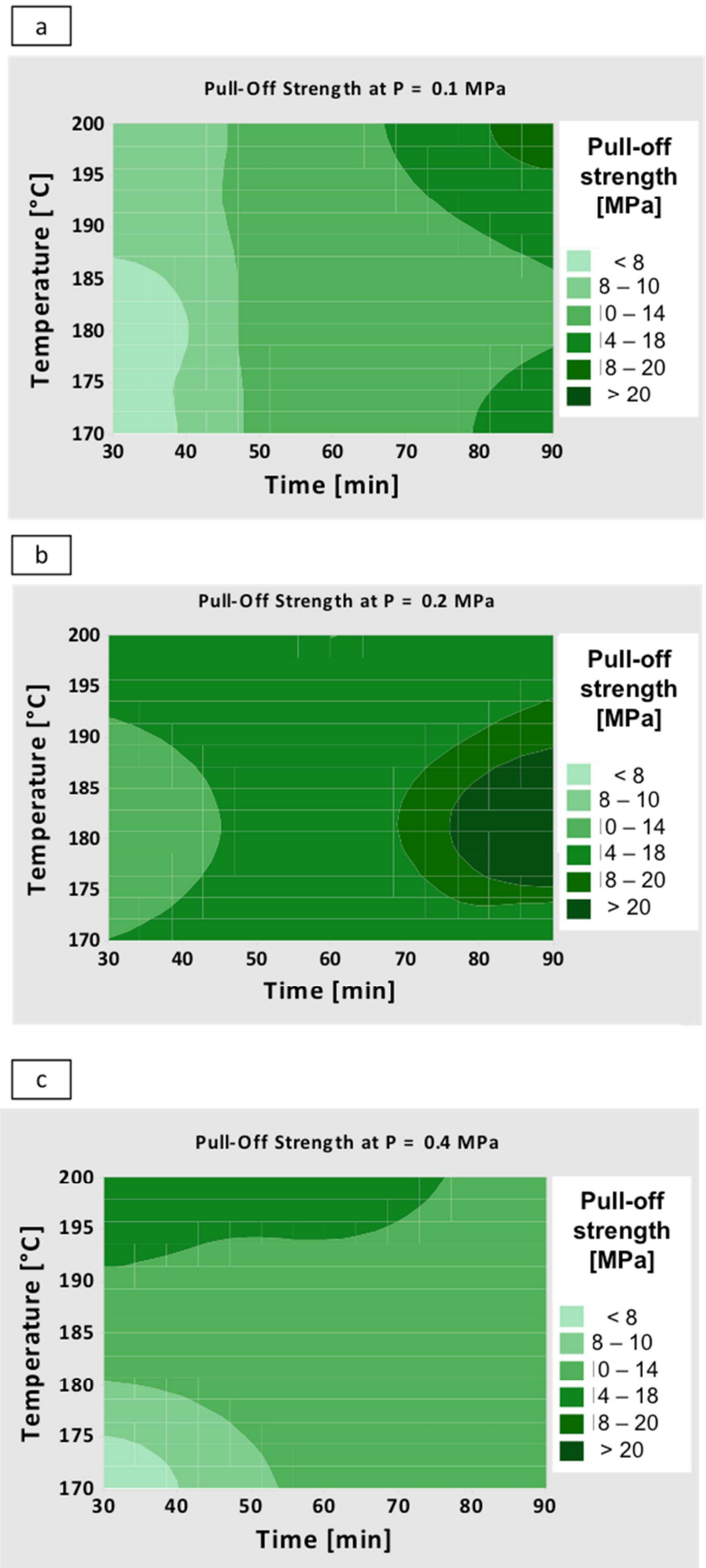

Figure 4: Contour charts showing the mutual effect of the hot-pressing time and temperature at constant pressures of $0.1 \mathrm{MPa}$ (a), $0.2 \mathrm{MPa}$ (b) and $0.4 \mathrm{MPa}$ (c) on the Ti/PMMA/Ti pull -off st $r$ ength. 

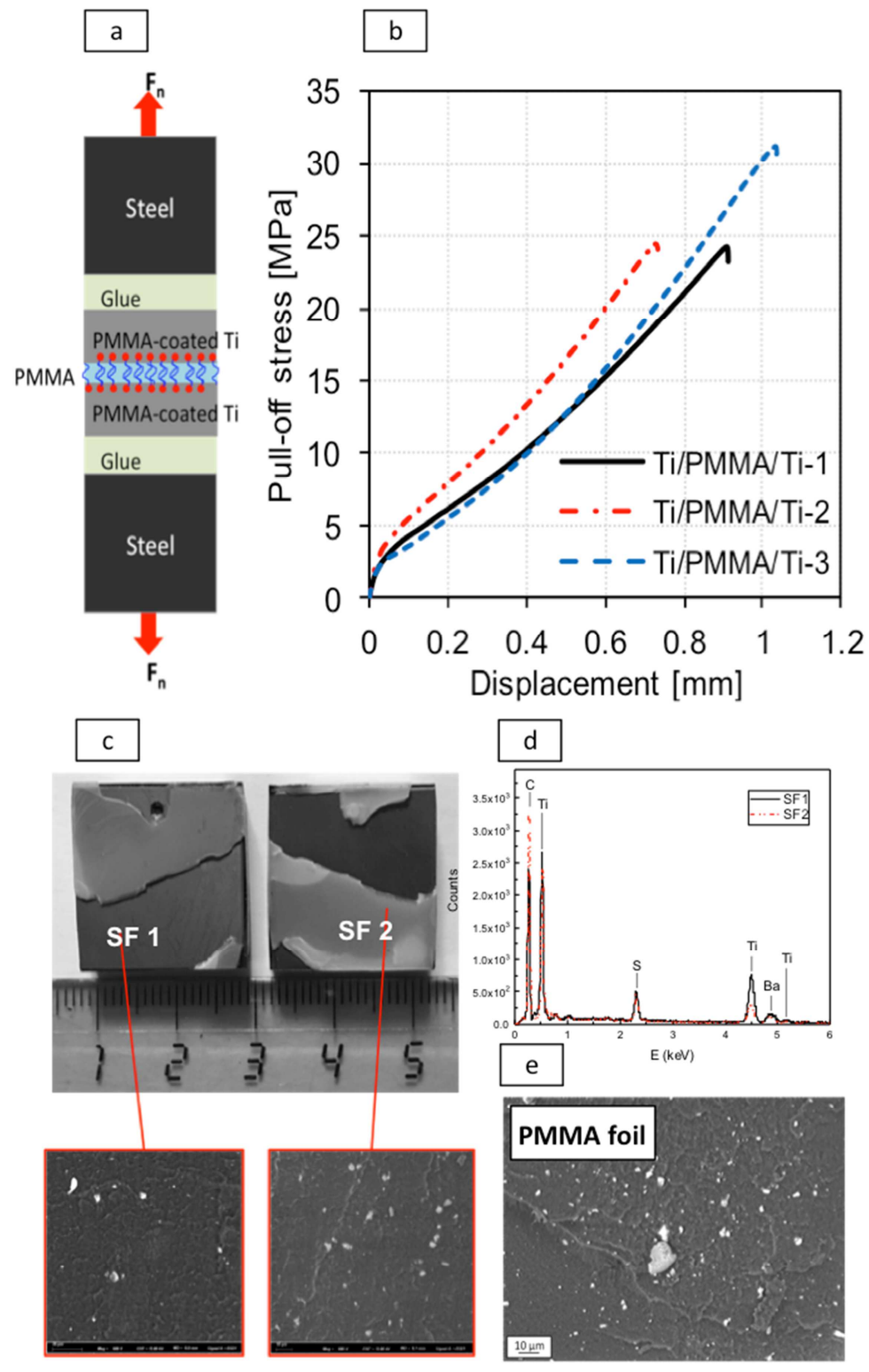

Figure 5: a) schematization of the pull-off test set-up. The external part of the sandwich was fixed on a steel support required to insert the sample in the universal testing machine. b) Stress-strain curves obtained performing the pull-off tests of three Ti/PMMA/Ti sandwiches produced with the ident ified optimum conditions. c) Fracture surfaces of a representative Ti/PMMA/Ti sandwich after pull-off test together with two SEM micrographs recorded on both the sides of the fracture surfaces.d) EDX spectra a Ti/PMMMA/Ti sandwich surface fracture (black 1 ine corresponds to point SF1 and the red 
one to SF2). e) SEM micrograph of the PMMA foil used as core material (white spots correspond to $\mathrm{Ba} \mathrm{SO}_{4}$ fill lers).
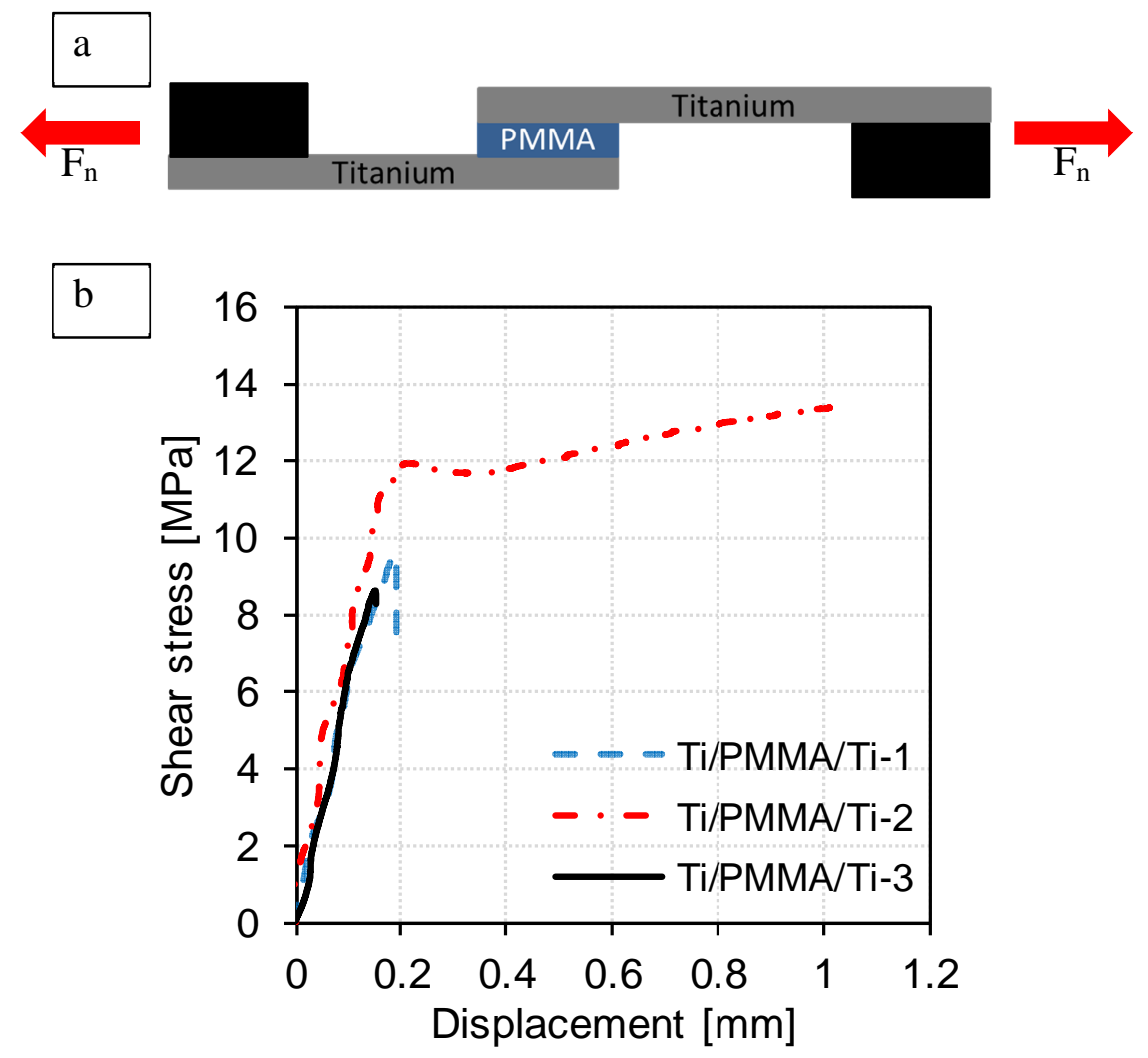

c
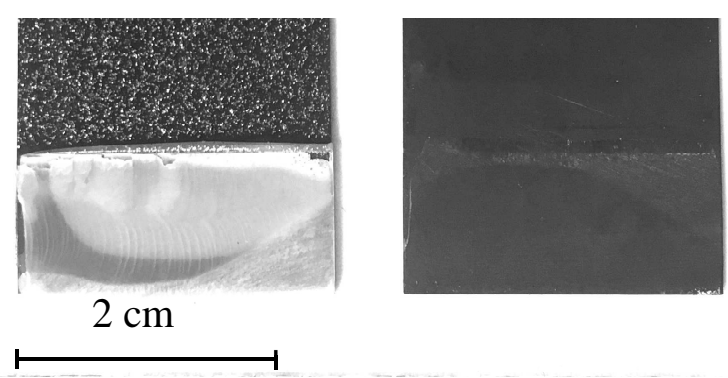

Figure 6: a) Schematization of the sample geometry used to perform shear test s. b) Shear stress-displ acement for three sandwich samples (Ti/PMMA/Ti: 0.4/0.5/0.4) produced using the 
opt imum conditions $\left(\mathrm{T}=180^{\circ} \mathrm{C}, \mathrm{t}=90 \mathrm{~min}, \mathrm{p}=0.2 \mathrm{MPa}\right)$. c) Represent at ive fract ure surfaces after shear tests. 


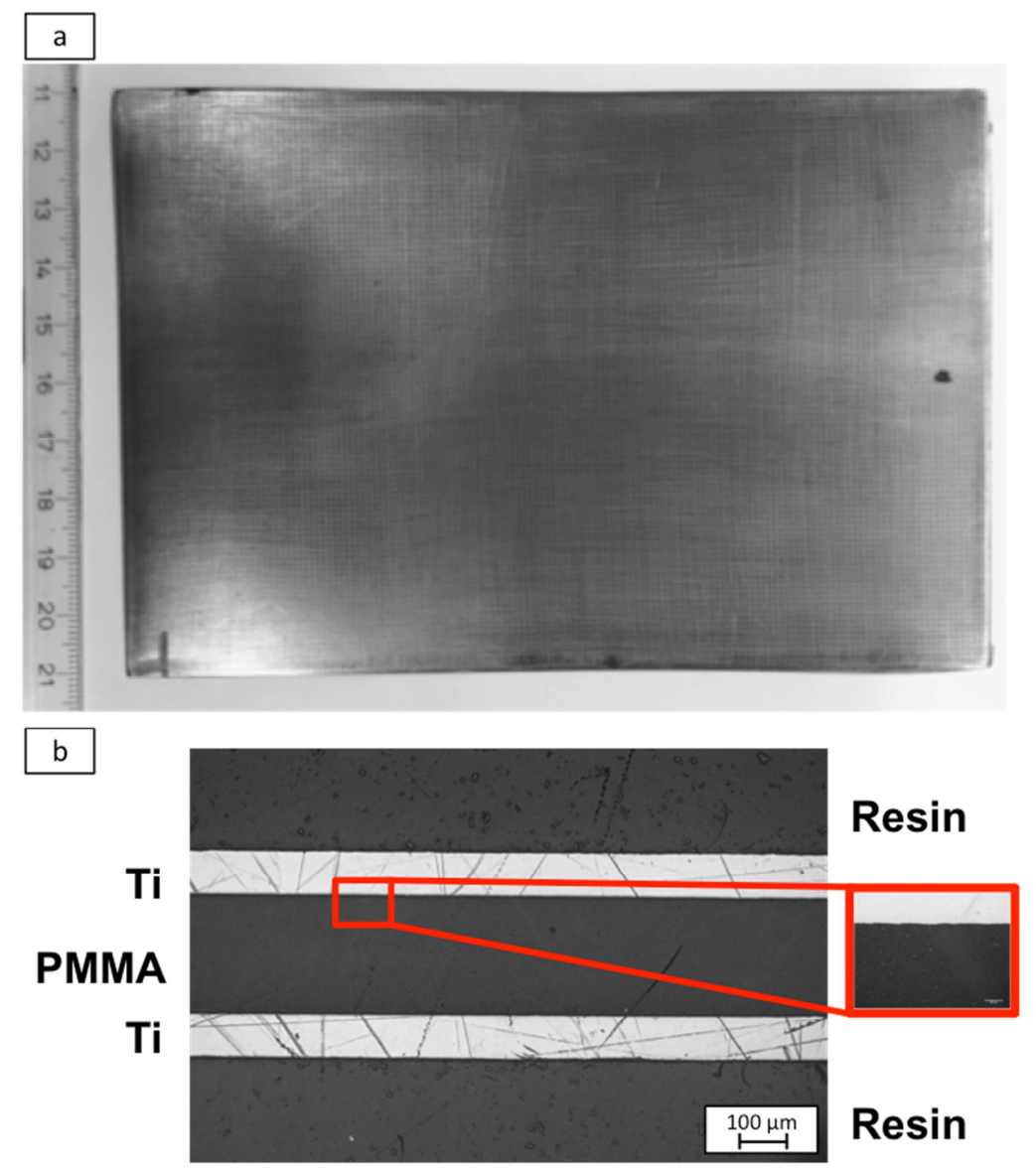

Figure 7: A6-sized Ti/PMMA/Ti sandwich (a) and an opt ical micrograph of it s cross-sect ion (b). 


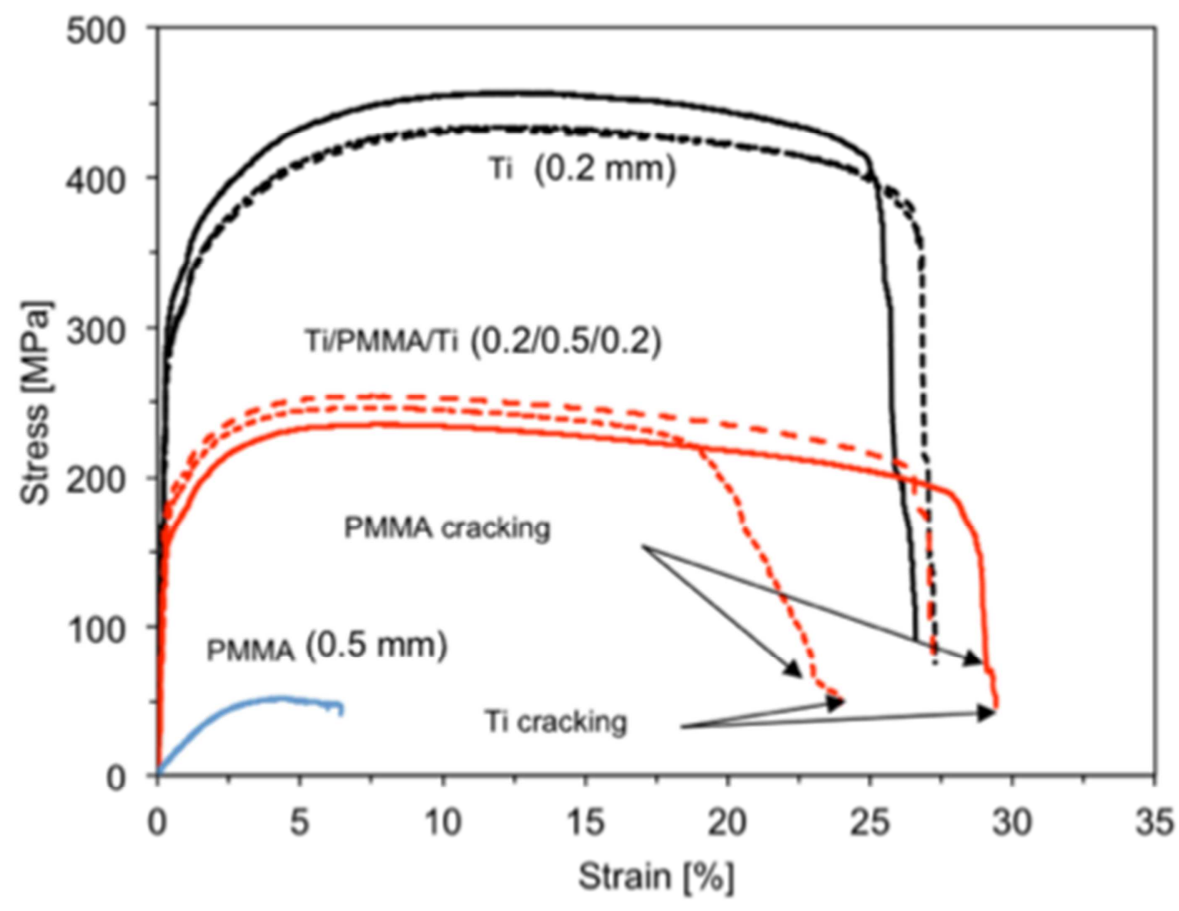

Figure 8: Stress-strain curves of Ti (black curves, upper three ones), PMMA (blue curve, lower one) as well as Ti/PMMA/Ti (red curves, medium three ones) samples obtained perfor ming tensile test s. 


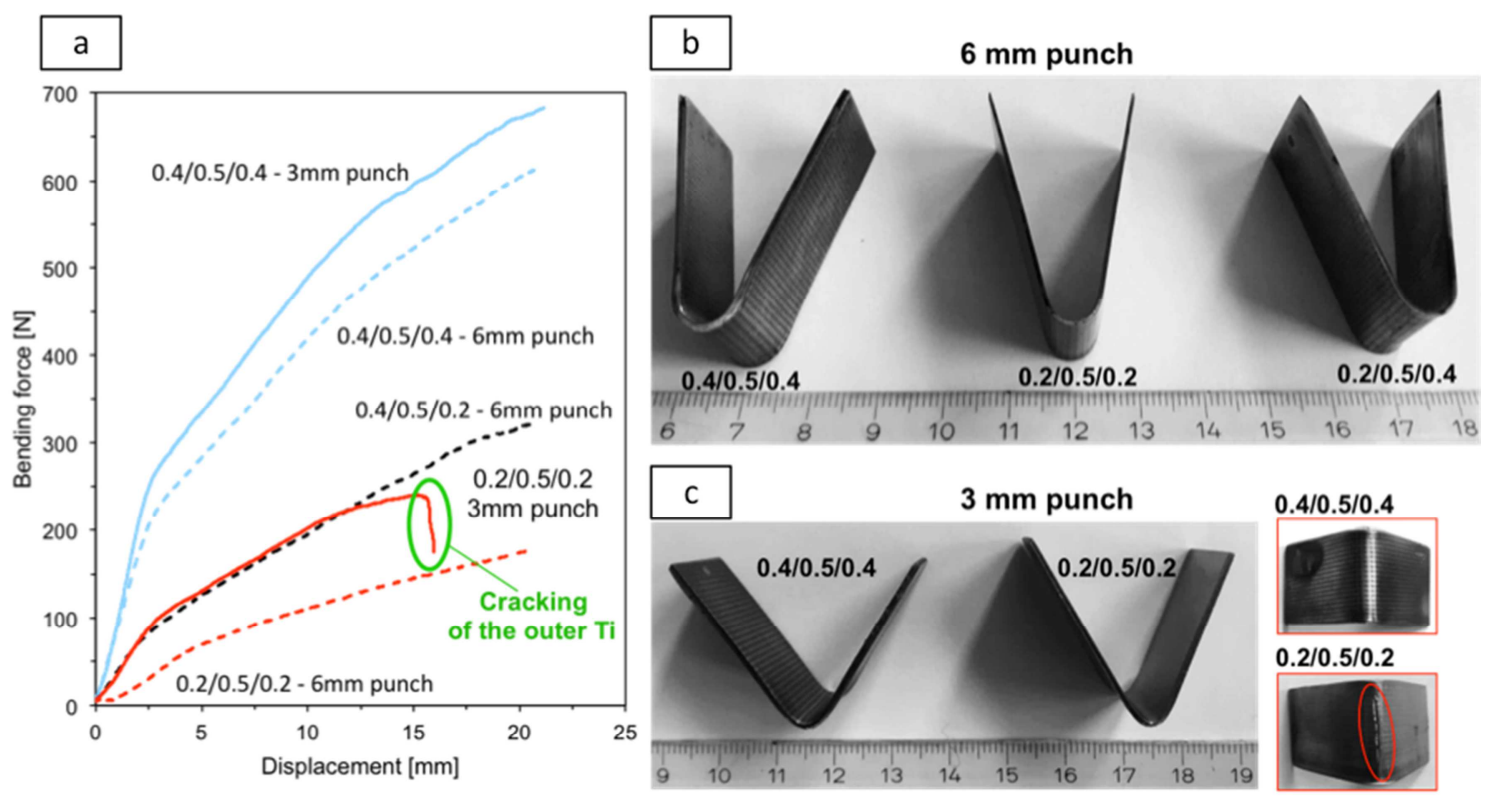

Figure 9: a) Bending force - displ acement curves for different thickness combinations and punch diameters of $3 \mathrm{~mm}$ and $6 \mathrm{~mm}$. b) Ti/PMMA/Ti sandwiches bent up to $180^{\circ}$ with a $6 \mathrm{~mm}$ punch.c) Ti/PMMA/Ti sandwiches bent up to about $80^{\circ}$ with a $3 \mathrm{~mm}$ punch . 


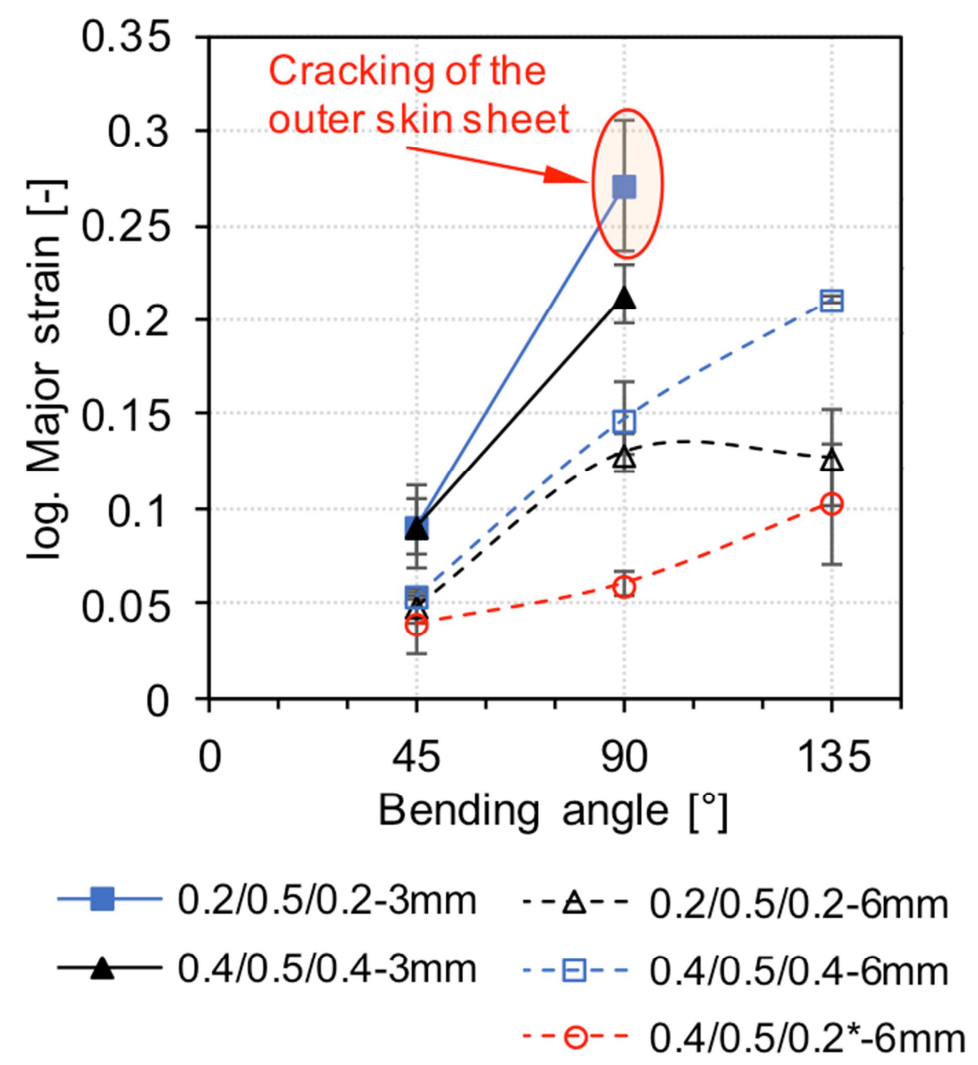

Figure 10: Average maximum major strains of the bent samples in cor $r$ elat ion with $t h e$ punch size, bending angle and skin/core thickness configur at ions. 


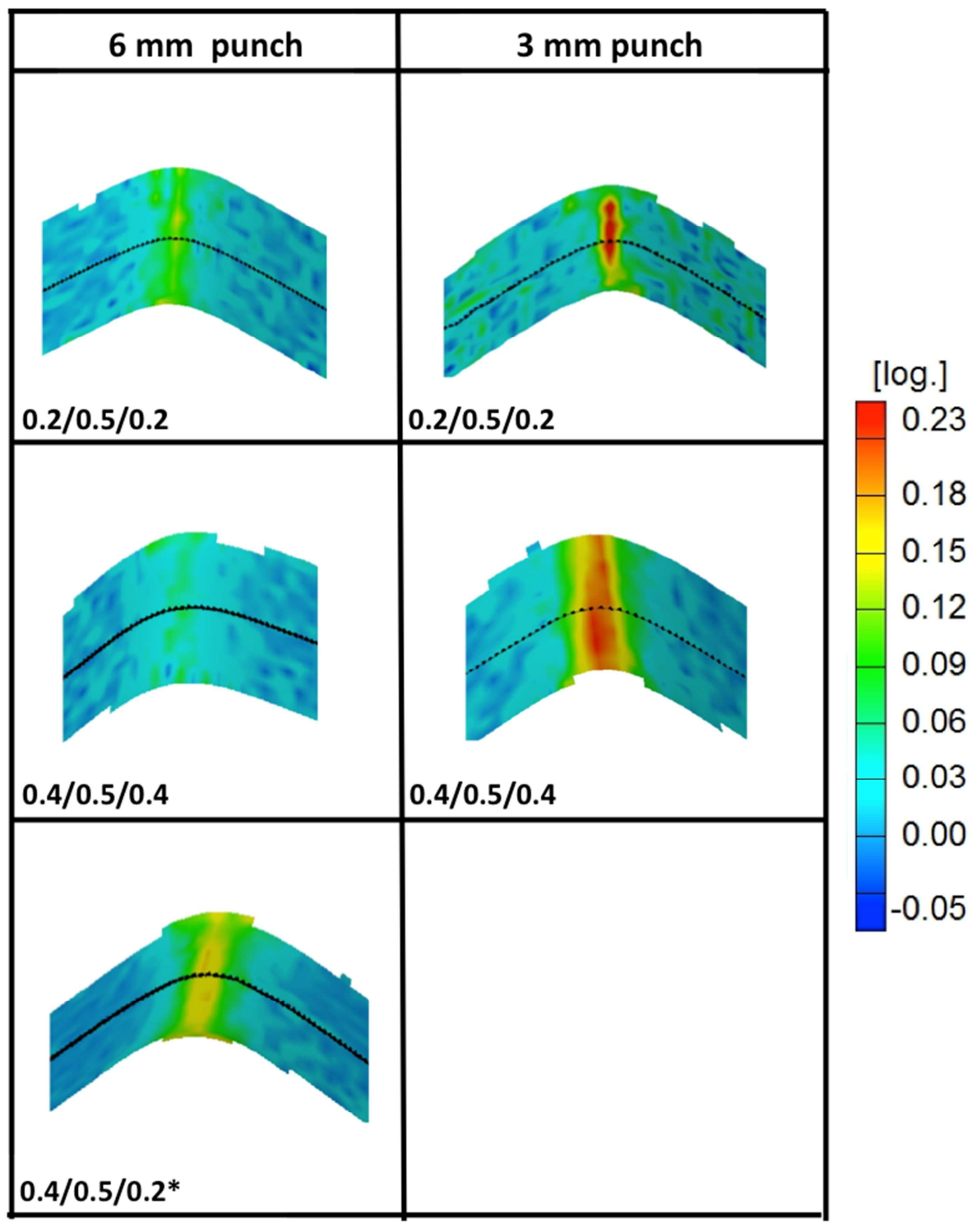

Figure 11: Phot ogrammet $r$ ic images of the bent samples at $90^{\circ}$. *: indicat ing the Tiskin sheet in contact with the punch during the bending test. 


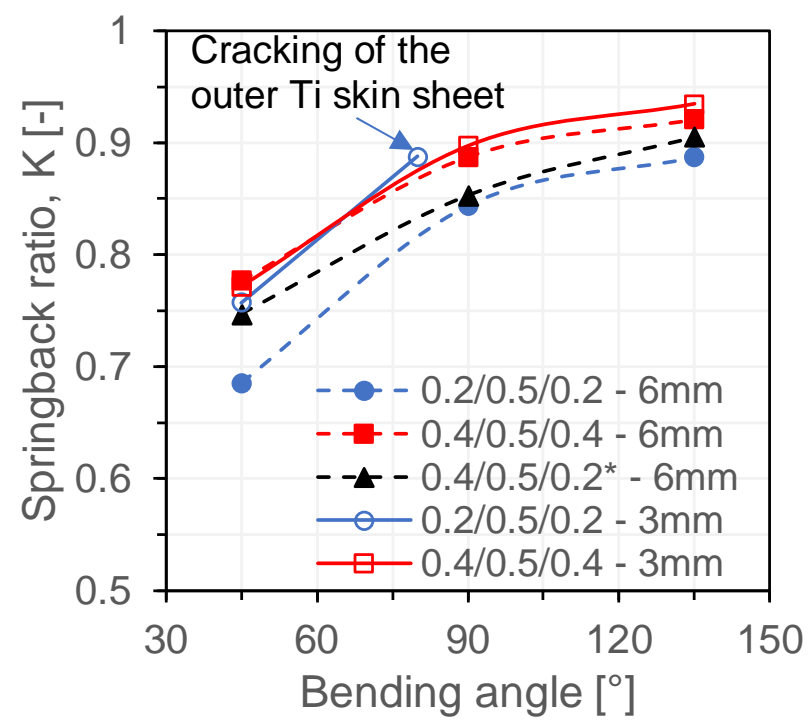

Figure 12: Springback rat io of the Ti/PMMA/Ti sandwiches in correlat ion with the skin/core thickness and the bending angles $\left(45^{\circ}, 90^{\circ}\right.$ and $135^{\circ}$ ). Punch diameters: $3 \mathrm{~mm}$ (sol id 1 ines), 6 $\mathrm{mm}(\mathrm{d}$ ot ted $\mathrm{l}$ ines). 

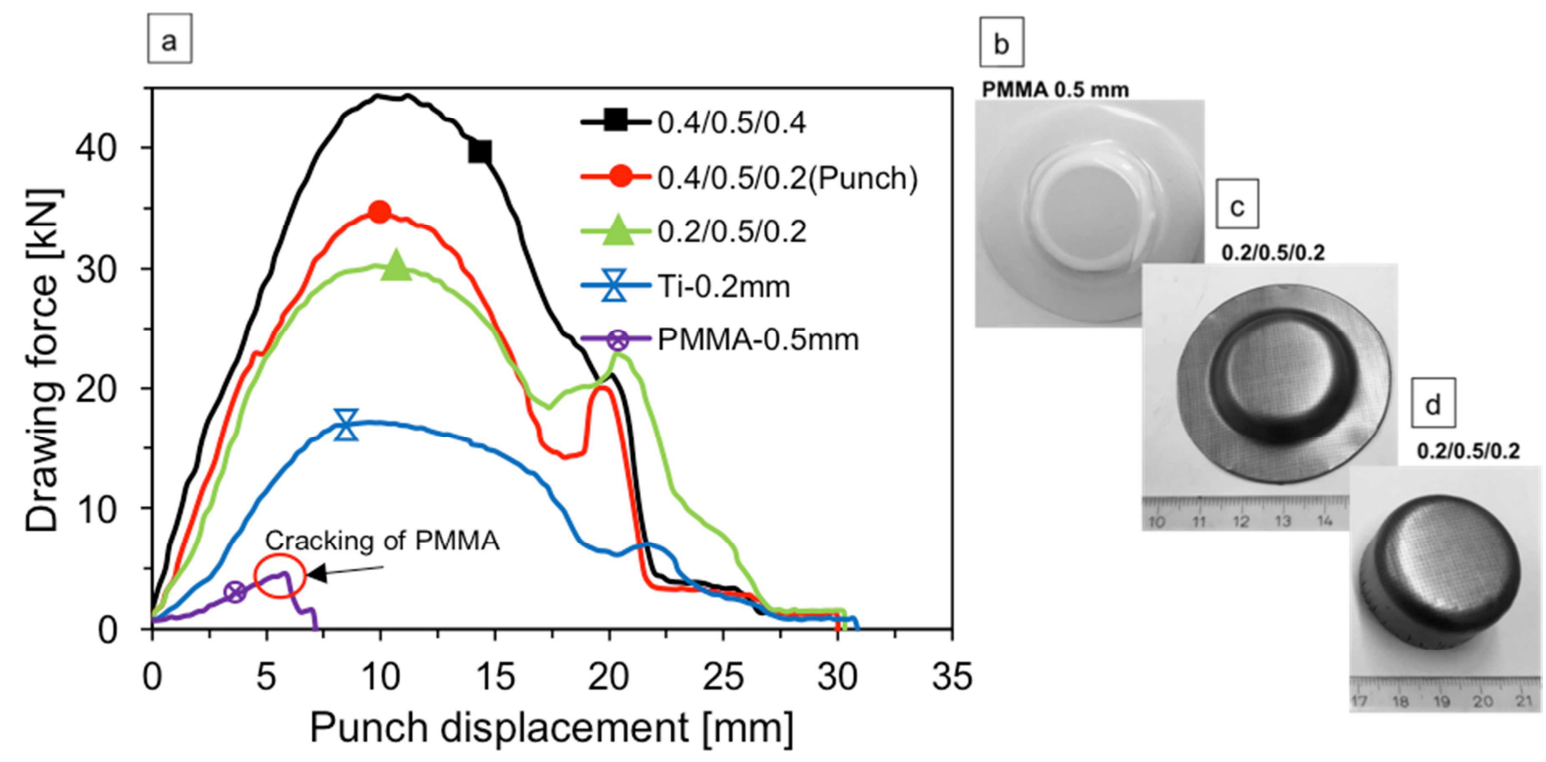

Figure 13: a) Dr a wing for ce-punch displ acement curves for the test ed combinat ions $\left(\beta_{0}=1,8\right)$, b) Cracking of the PMMA foil $0.5 \mathrm{~mm}$ thick, drawn upt o a displ acement of $6 \mathrm{~mm}$. c) 0.2/0.5/0.2 Ti/PMMA/Ti, drawn up to a displ a cement of $6 \mathrm{~mm}$. d) 0.2/0.5/0.2 Ti/PMMA/Ti co mpl et el y drawn. 

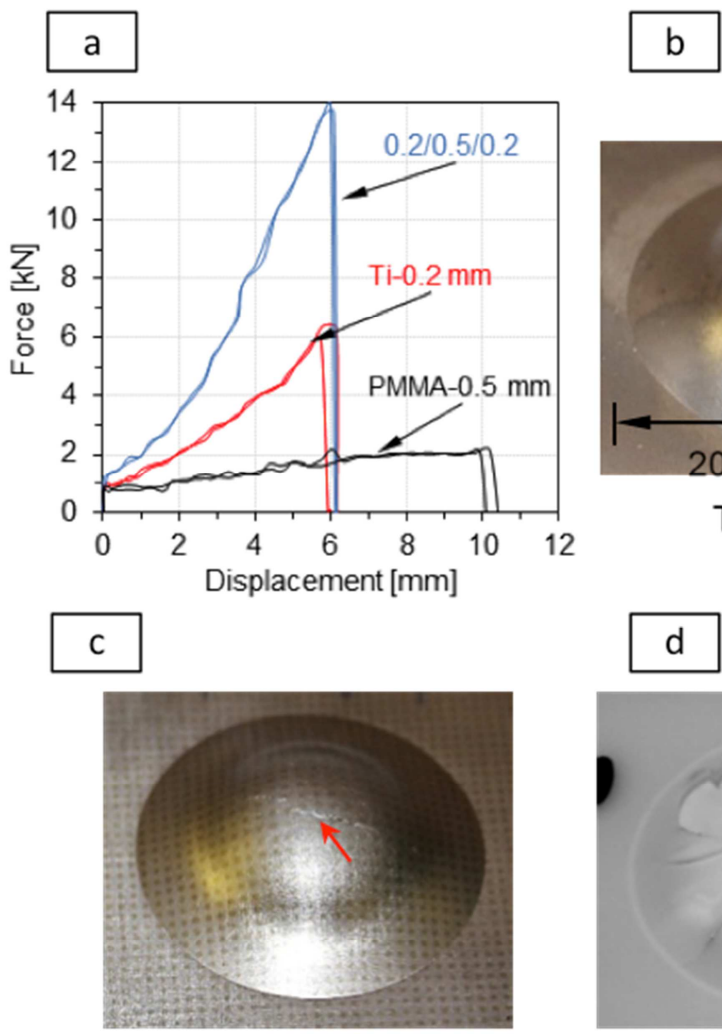

Ti/PMMA/Ti: 0.2/0.5/0.2

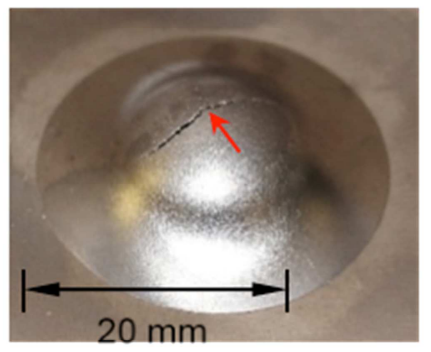

$\mathrm{Ti}-0.2 \mathrm{~mm}$

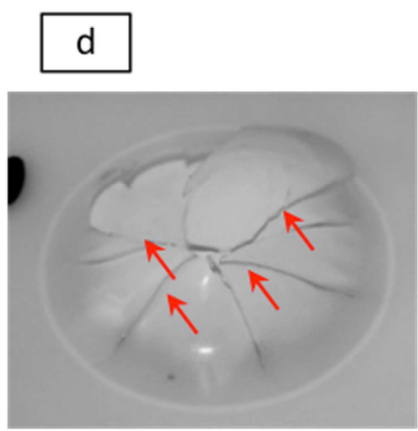

PMMA-0.5 mm

Figure 14: a) Drawing force-punch displ acement curves for the tested materials according to Erichsen test and b) the cracked samples showing the central fail ure location (two sampl es/each condit ion were tested). 


\section{Tables}

Table 1:Experiment al para meters used for the Ti/PMMA/Ti sandwich production - according to the DoEpl an - and their corresponding adhesion st rengthevaluated in pull-off tests.

\begin{tabular}{|c|c|c|c|}
\hline $\begin{array}{c}\text { Temper a t u } \\
\text { r e } \\
{\left[{ }^{\circ} \mathrm{C}\right]}\end{array}$ & $\begin{array}{l}\text { Time } \\
{[\mathrm{min}]}\end{array}$ & $\begin{array}{c}\text { Pressu } \\
\text { r e } \\
{[\mathrm{MPa}]}\end{array}$ & $\begin{array}{l}\text { Pull -off } \\
\text { st r ength } \\
{[\mathrm{MPa}]}\end{array}$ \\
\hline \multirow{7}{*}{170} & \multirow{2}{*}{30} & 0.1 & $7 \pm 1$ \\
\hline & & 0.4 & $7 \pm 1$ \\
\hline & \multirow{2}{*}{60} & 0.1 & $11 \pm 4$ \\
\hline & & 0.2 & $16 \pm 6$ \\
\hline & \multirow{3}{*}{90} & 0.1 & $16 \pm 7$ \\
\hline & & 0.2 & $16 \pm 5$ \\
\hline & & 0.4 & $11 \pm 1$ \\
\hline \multirow{6}{*}{180} & \multirow{2}{*}{30} & 0.1 & $6 \pm 2$ \\
\hline & & 0.2 & $12 \pm 5$ \\
\hline & \multirow{2}{*}{60} & 0.1 & $12 \pm 2$ \\
\hline & & 0.4 & $10 \pm 1$ \\
\hline & \multirow{2}{*}{90} & 0.2 & $24 \pm 1$ \\
\hline & & 0.4 & $13 \pm 3$ \\
\hline \multirow{6}{*}{200} & \multirow{3}{*}{30} & 0.1 & $9 \pm 1$ \\
\hline & & 0.2 & $14 \pm 1$ \\
\hline & & 0.4 & $16 \pm 8$ \\
\hline & \multirow{2}{*}{60} & 0.2 & $14 \pm 3$ \\
\hline & & 0.4 & $15 \pm 5$ \\
\hline & 90 & 0.1 & $19 \pm 2$ \\
\hline
\end{tabular}


Table 2: Tensile properties of the mono-materials (Ti, PMMA) and the sandwiches (Ti/PMMA/Ti) as well as theoretical values (Ti/PMMA/Ti*1 ${ }^{1}$ Ti/PMMA/Ti*2) proposed using the RoM providing mechanical properties close to the cortical bone $(E=15-30 G P a)^{52,53}$. Where, $f_{\text {PMMA }}$ : vol ume fraction, YS and UTS: yield strength and ultimate tensile st rength, E: Young's modulus and ER: el ongation to rupture.

\begin{tabular}{|l|c|c|c|c|c|c|c|c|c|}
\hline \multirow{2}{*}{ Sample } & $\begin{array}{c}\text { Thickness } \\
{[\mathrm{mm}]}\end{array}$ & $\begin{array}{c}f_{P M M A} \\
{[-]}\end{array}$ & \multicolumn{2}{|c|}{ E [GPa] } & \multicolumn{2}{c|}{ UTS [MPa] } & \multicolumn{2}{c|}{ YS [MPa] } & ER[\%] \\
\hline $\mathrm{Ti}$ & 0.2 & 0 & $108 \pm 7$ & & $441 \pm 14$ & - & $289 \pm 15$ & - & $27 \pm 1$ \\
\hline PMMA & 0.5 & 1.0 & $2.0 \pm 0.1$ & & $51 \pm 1$ & - & - & - & $6 \pm 1$ \\
\hline Ti/PMMA/Ti & $\begin{array}{c}0.9 \\
(0.2 / 0.5 / 0.2)\end{array}$ & 0.55 & $51 \pm 3$ & 55 & $245 \pm 10$ & 246 & $179 \pm 14$ & 170 & $27 \pm 3$ \\
\hline Ti/PMMA/Ti* & $\begin{array}{c}1.4 \\
(0.2 / 1.0 / 0.2)\end{array}$ & 0.71 & - & 32 & - & 162 & - & 119 & $27 * *$ \\
\hline Ti/PMMA/Ti*2 & $\begin{array}{c}2.1 \\
(0.4 / 1.5 / 0.2)\end{array}$ & 0.71 & - & 32 & - & 162 & - & 119 & $27 * *$ \\
\hline *: calculated sandwich combination; **: expected, based on the strain at failure of the Ti sheet \\
\hline
\end{tabular}

Table 3: Deep-drawing parameters used for the monomaterials (Ti and PMMA) as well as the Ti/PMMA/Ti sandwich in addit ion to the obt ained result $\mathrm{s}$. Drawing rat io, $\beta_{0}=1.8$.

\begin{tabular}{|c|c|c|c|c|}
\hline $\begin{array}{l}\text { Sample } \\
\text { notation }\end{array}$ & $\begin{array}{l}\text { Thickness } \\
{[\mathrm{mm}]}\end{array}$ & $\begin{array}{c}\text { Blank holding } \\
\text { force }[\mathrm{kN}]\end{array}$ & $\begin{array}{l}\text { Max. drawing } \\
\text { force }[\mathrm{kN}]\end{array}$ & $\begin{array}{l}\text { Drawing depth } \\
{[\mathrm{mm}]}\end{array}$ \\
\hline $\mathrm{Ti}$ & 0.2 & 10 & $17 \pm 2$ & Drawn cup \\
\hline PMMA & 0.5 & 8 & $5 \pm 1$ & $\sim 6 \mathrm{~mm}$ cracking \\
\hline Ti/PMMA/Ti & $0.4 / 0.5 / 0.4$ & 8 & $45 \pm 1$ & \multirow{3}{*}{$\begin{array}{l}\text { Drawn cup: } \\
\text { - No cracking of } \\
\text { the skin sheets } \\
\text { - Cracking of the } \\
\text { PMMA core }\end{array}$} \\
\hline Ti/PMMA/Ti & $0.4 * / 0.5 / 0.2$ & 8 & $35 \pm 1$ & \\
\hline Ti/PMMA/Ti & $0.2 / 0.5 / 0.2$ & 7 & $30 \pm 1$ & \\
\hline
\end{tabular}


2. Biocompatible Ti/PMMA/Ti sandwich production

\section{PMMA}

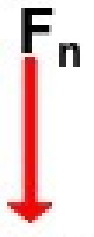

PMMA-coated Ti

PMMA-coated Ti

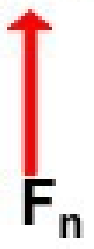

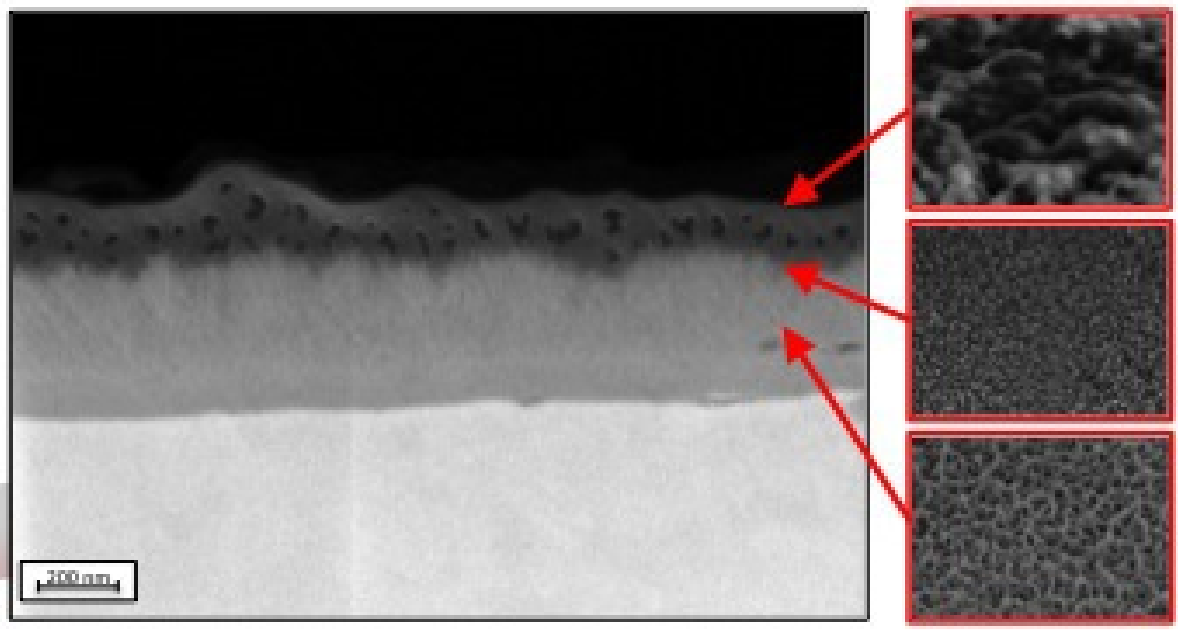
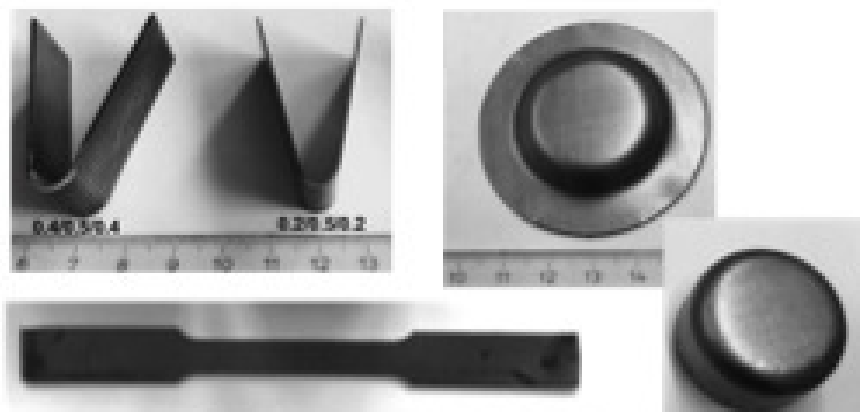

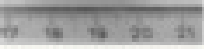

3. Mechanical testing of the bio-TI/PMMA/TI sandwiches 